\title{
Biomarkers for the diagnosis and management of heart failure
}

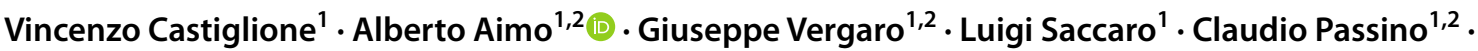 \\ Michele Emdin ${ }^{1,2}$
}

Accepted: 6 April 2021 / Published online: 14 April 2021

(c) The Author(s) 2021

\begin{abstract}
Heart failure (HF) is a significant cause of morbidity and mortality worldwide. Circulating biomarkers reflecting pathophysiological pathways involved in HF development and progression may assist clinicians in early diagnosis and management of HF patients. Natriuretic peptides (NPs) are cardioprotective hormones released by cardiomyocytes in response to pressure or volume overload. The roles of B-type NP (BNP) and N-terminal pro-B-type NP (NT-proBNP) for diagnosis and risk stratification in HF have been extensively demonstrated, and these biomarkers are emerging tools for population screening and as guides to the start of treatment in subclinical HF. On the contrary, conflicting evidence exists on the role of NPs as a guide to HF therapy. Among the other biomarkers, high-sensitivity troponins and soluble suppression of tumorigenesis-2 are the most promising biomarkers for risk stratification, with independent value to NPs. Other biomarkers evaluated as predictors of adverse outcome are galectin-3, growth differentiation factor 15, mid-regional pro-adrenomedullin, and makers of renal dysfunction. Multi-marker scores and genomic, transcriptomic, proteomic, and metabolomic analyses could further refine HF management.
\end{abstract}

Keywords Biomarkers $\cdot$ Heart failure $\cdot$ Natriuretic peptides $\cdot$ Troponin $\cdot$ SST2 $\cdot$ Inflammation

Heart failure (HF) is a syndrome characterized by the inability of the heart to pump enough blood and oxygen to support the metabolic demands of other organs [1]. HF affects around 64 million of patients worldwide, and its prevalence is increasing due to population ageing, the growing burden of comorbidities and risk factors for HF, and the longer survival after myocardial infarction [2].

HF is commonly classified based on left ventricular ejection fraction (LVEF) into the categories of HF with preserved (HFpEF; LVEF $\geq 50 \%$ ), mid-range (HFmrEF; LVEF 40-49\%), and reduced ejection fraction (HFrEF; LVEF < 40\%) [2]. HFpEF is predominantly characterized by diastolic dysfunction and often results from heart damage due to comorbidities (e.g., obesity, chronic kidney disease (CKD), chronic obstructive pulmonary disease) or accumulation disorders (e.g., cardiac amyloidosis). HFrEF, on the other hand, is characterized prevalently by systolic

\section{Alberto Aimo}

albertoaimo@libero.it; a.aimo@santannapisa.it

1 Institute of Life Sciences, Scuola Superiore Sant'Anna, Pisa, Italy

2 Fondazione Toscana Gabriele Monasterio, Pisa, Italy dysfunction, secondary to a direct heart damage (such as an acute coronary syndrome), a cardiomyopathy or a valve disease [2]. While the pathophysiology of HFpEF is likely multifactorial, an imbalance in the neuroendocrine systems regulating cardiovascular homeostasis plays a central role in HFrEF. The sympathetic nervous system (SNS) and the renin-angiotensin-aldosterone system (RAAS) are overactivated and are not adequately counterbalanced by the increased release of natriuretic peptides (NPs). This imbalance promotes structural alterations leading to progressive hypertrophy and dilation of cardiac chambers. These alterations have detrimental effects on cardiac pump function, and ultimately lead to symptom development, as well as an increased susceptibility to arrhythmias and cardiac conduction disorders [1].

Thanks to the introduction of pharmacological therapies (beta-blockers, angiotensin-converting enzyme (ACE) inhibitors or angiotensin receptor blockers, mineralocorticoid receptor antagonists, neprilysin inhibitors, and, recently, sodium-glucose 2 co-transport inhibitors) and devices (implantable cardioverter defibrillator and cardiac resynchronisation therapy), the survival of HF patients has progressively improved. A careful use of biomarkers might 
help refine the management of patients with HF and further improve their prognosis.

\section{Characteristics of an ideal biomarker}

The term "biomarker" (from "biological marker") was coined in 1989 to identify a "measurable and quantifiable biological parameter used to assess the health and physiology of patients in terms of disease risk and diagnosis" [3]. In 2001, the National Institute of Health defined a biomarker as "a characteristic that is objectively measured and evaluated as an indicator of normal biological processes, pathogenic processes, or pharmacologic responses to a therapeutic intervention" [4]. A further definition by the World Health Organization states that "a biomarker is any substance, structure or process that can be measured in the body or its products and influence or predict the incidence of outcome or disease" [5].

Morrow and de Lemos summarized the characteristics of clinically useful biomarkers [6]. Ibrahim and Januzzi then adapted these criteria to the specific setting of HF: (1) the biomarker should be measured accurately; (2) the assay should be easily available and be interpretable at a reasonable cost, results should be available quickly, biological variation should be defined, imprecision should be low, reference limits should be well defined, possible pre-analytical, analytical and post-analytical sources of error well known; (3) a new biomarker should explore an important disease pathway in HF; (4) the analyte of interest should provide information that is not available through objective examination and laboratory investigation; (5) a new biomarker should guide the diagnosis, risk stratification, or management of HF [7].

Biomarkers can serve as "antecedent biomarkers" (predicting future disease development), screening biomarkers (identifying subclinical disease), diagnostic biomarkers (recognizing clinically manifest disease), staging biomarkers (defining disease severity), prognostic and therapeutic biomarkers (predicting disease evolution and the response to therapy, respectively), as well as inclusion/exclusion and outcome criteria for clinical trials $[1,3]$ (Table 1).

Although imaging findings, signals, functional tests and genetic variants can all be defined as "biomarkers," this review will focus on circulating biomarkers [1]. Since Braunwald's first studies in the 1950s on C-reactive protein (CRP) in HF [8], hundreds of molecules have been studied, but only B-type natriuretic peptide (BNP) and N-terminal pro-B-type natriuretic peptide (NT-proBNP) come close to the characteristics of "ideal" HF biomarkers, and are often regarded as the reference standard against which other potential biomarkers must be evaluated.

\section{Natriuretic peptides}

The discovery of atrial natriuretic peptide (ANP) in 1981 [9] and then BNP [10] showed that the heart has an endocrine function, and paved the way to the characterization of these molecules as HF biomarkers.

\section{BNP, NT-proBNP}

BNP and NT-proBNP are synthesized from a pre-hormone of 134 amino acids, encoded by the NPPB gene. Once a residue of 26 amino acids is cleaved, $\mathrm{BNP}_{1-108}$ is produced, which is converted by the enzymes furin or corin into $\mathrm{BNP}_{1-32}$, the biologically active molecule, and NT-proBNP ${ }_{1-76}$, its inactive N-terminal fragment (Fig. 1). BNP is produced primarily by ventricular cardiomyocytes in response to volume or pressure overload [11]. Circulating BNP and NT-proBNP levels are normally very low, but increase significantly in HF patients as a mechanism to restore normal hemodynamics. BNP promotes arterial vasodilation, dieresis, and natriuresis, exerts anti-hypertrophic and anti-fibrotic effects, and counteracts the activation of RAAS, SNS and the endothelin systems [11]. BNP binds to NP receptor A (NPR-A) and NPR-B, which have guanylatecyclase activity. Around $25 \%$ of BNP is excreted unmodified by the kidneys. The remaining part is eliminated after binding to the NPR-C receptor or through enzymatic degradation by neprilysin. Conversely, NT-proBNP has only a passive excretion, mainly by the kidney. Due to their different clearance, NT-proBNP has a longer half-life (120 vs. $20 \mathrm{~min})$ and higher plasma concentrations (approximately 6 times) than BNP [11].

Table 1 Characteristics of an "ideal" biomarker and possible types of biomarkers in heart failure

\begin{tabular}{|c|c|}
\hline Characteristics of an "ideal" biomarker & Types of biomarkers \\
\hline $\begin{array}{l}\text { - Has been thoroughly tested } \\
\text { - Is cheap, easily measured and interpreted, with well-known characteristics } \\
\text { - Reflects a pivotal pathophysiological pathway } \\
\text { - Provides additional information to those already available } \\
\text { - Allows a better definition of heart failure diagnosis, prognosis or management }\end{array}$ & $\begin{array}{l}\text { - Antecedent biomarker } \\
\text { - Screening biomarker } \\
\text { - Diagnostic biomarker } \\
\text { - Staging biomarker } \\
\text { - Prognostic biomarker } \\
\text { - Treatment response biomarker } \\
\text { - Surrogate endpoint }\end{array}$ \\
\hline
\end{tabular}


Fig. 1 Processing of type B natriuretic peptides and their role as biomarkers in heart failure. BNP B-type natriuretic peptide, NT-proBNP N-terminal pro-B-type natriuretic peptide
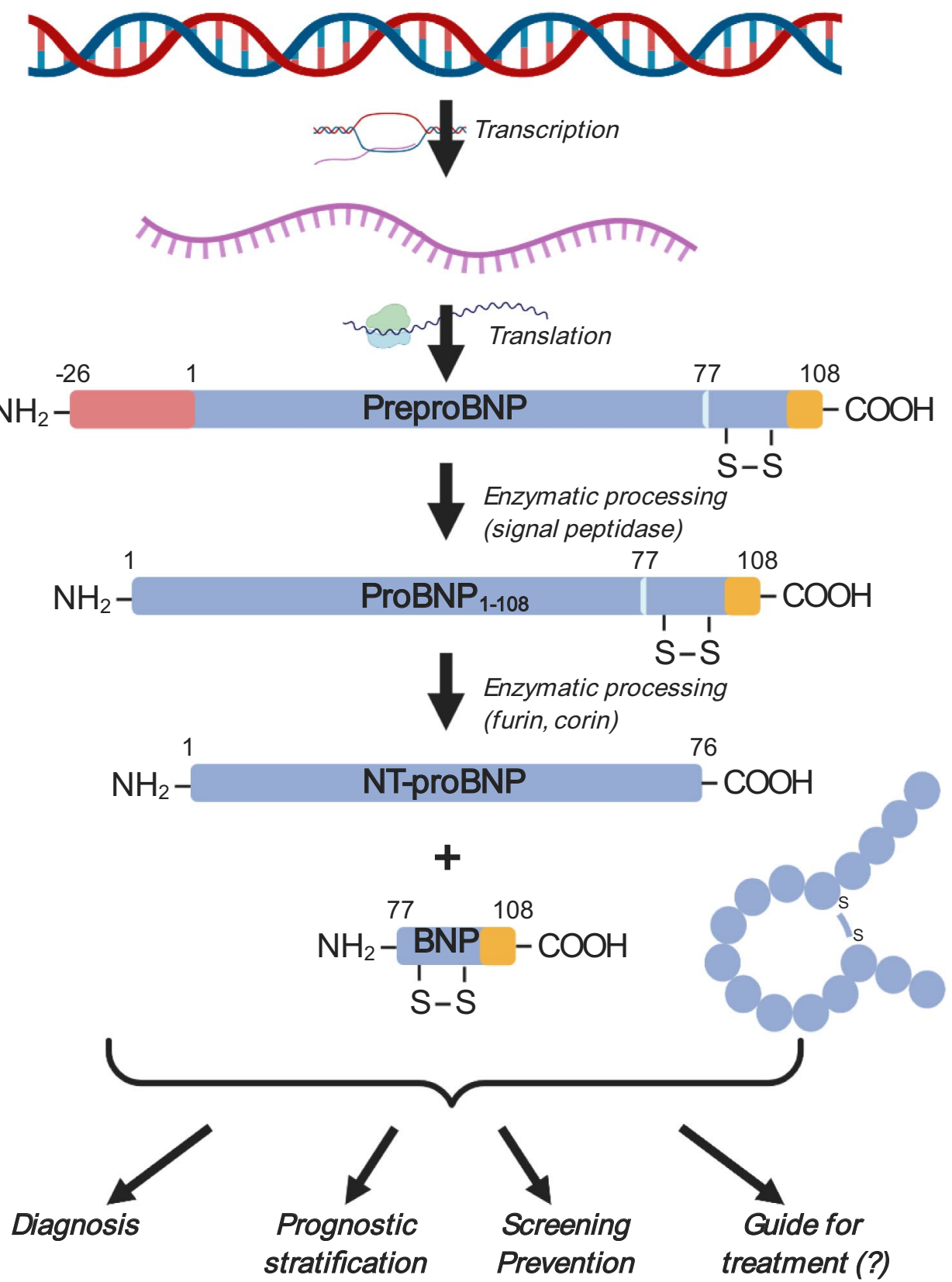

\section{Diagnosis}

In the Breathing Not Properly study, which included 1586 patients admitted to the emergency room for new-onset dyspnoea, BNP levels were significantly higher in subjects with acute HF, and plasma BNP increased in parallel with the New York Heart Association (NYHA) class. BNP had an area under the curve (AUC) of 0.91 for the diagnosis of HF; a cutoff of $100 \mathrm{ng} / \mathrm{L}$ showed a better diagnostic performance (90\% sensitivity, $76 \%$ specificity, $83 \%$ accuracy) than previous diagnostic scores (National Health and Nutrition Examination Survey and Framingham criteria) [12]. Similar results were reported for NT-proBNP in the N-terminal Pro-BNP
Investigation of Dyspnea in the Emergency department (PRIDE) study, evaluating 600 patients admitted to the emergency department for dyspnoea. NT-proBNP $<300 \mathrm{ng} / \mathrm{L}$ ruled out effectively acute HF (99\% negative predictive value [NPV]), and rule-in cutoffs of $450 \mathrm{ng} / \mathrm{L}$ in subjects with $<50$ years ( $93 \%$ sensitivity, $95 \%$ specificity, $95 \%$ accuracy) and $900 \mathrm{ng} / \mathrm{L}$ in subjects with $\geq 50$ years ( $91 \%$ sensitivity, $80 \%$ specificity, $85 \%$ accuracy) were proposed [13]. Indeed, NP levels tend to increase in the elderly, probably because of age-dependent decreases in left ventricular (LV) compliance and kidney function. The use of age-specific cutoffs was supported by the International Collaborative study of NT-proBNP (ICON), where the use of different thresholds 
Table 2 Indications for the use of biomarkers in the ACC/AHA 2017 and ESC 2016 guidelines for heart failure management

\begin{tabular}{|c|c|c|c|c|}
\hline Biomarker & Guidelines & Indication & $\begin{array}{l}\text { Recommendation } \\
\text { class }\end{array}$ & $\begin{array}{l}\text { Level of } \\
\text { evidence }\end{array}$ \\
\hline \multirow[t]{5}{*}{ BNP or NT-proBNP } & ESC & Diagnosis & I & A \\
\hline & ACC/AHA & & IIa & $\mathrm{C}$ \\
\hline & \multirow[t]{3}{*}{ ACC/AHA } & Prognostic stratification at admission (acute HF) & I & A \\
\hline & & Prognostic stratification at discharge (acute $\mathrm{HF}$ ) & IIa & B \\
\hline & & Screening/prevention & IIa & B \\
\hline MR-proANP & ESC & Diagnosis & I & A \\
\hline \multirow[t]{2}{*}{ hs-TnI/T } & ESC & Diagnostic support (acute HF) & I & $\mathrm{C}$ \\
\hline & ACC/AHA & Prognostic stratification at admission (acute and chronic HF) & I & A \\
\hline sST2, galectin-3 & ACC/AHA & Prognostic stratification (acute and chronic HF) & IIb & B \\
\hline
\end{tabular}

ACC/AHA American College of Cardiology/American Heart Association, BNP brain natriuretic peptide, ESC European Society of Cardiology, $h s-T n I / T$ high-sensitivity-troponin I/T, MR-proANP mid-regional pro-atrial natriuretic peptide, NT-proBNP N-terminal pro-B-type natriuretic peptide, $s S T 2$ soluble suppression of tumorigenesis-2

by age groups $(\geq 450, \geq 900$, and $\geq 1800 \mathrm{ng} / \mathrm{L}$ in subjects aged $<50,50-75$, and $>75$ years) increased the diagnostic performance of NT-proBNP [14].

HF outpatients have usually lower NP levels. In this setting, BNP and NT-proBNP were assessed mostly to rule out HF, with cutoffs that maximized NPV [15]. Age-stratified thresholds of NT-proBNP have been proposed also in chronic HF [16].

American College of Cardiology/American Heart Association (ACC/AHA) guidelines recommend the use of BNP and NT-proBNP to diagnose HF (class I, level of evidence (LOE) A), without indicating specific threshold values [17]. Conversely, European Society of Cardiology (ESC) guidelines recommend the use of BNP and NT-proBNP for the exclusion of HF (class IIa, LOE C), with reference values $<100 \mathrm{ng} / \mathrm{L}$ and $<300 \mathrm{ng} / \mathrm{L}$ for acute $\mathrm{HF}$, respectively, and $<35 \mathrm{ng} / \mathrm{L}$ and $<125 \mathrm{ng} / \mathrm{L}$ for chronic HF, respectively [2] (Table 2). Higher NP levels support the diagnosis of $\mathrm{HF}$, but further investigation is required to confirm the diagnosis. A recent ESC position paper on the use of NPs proposes both rule-out and rule-in cutoffs for BNP and NTproBNP, the latter with age-stratified values in acute HF [18] (Table 3).

\section{Risk stratification}

Numerous studies have demonstrated that NPs are useful to stratify the risk of HF patients. In the Acute Decompensated Heart Failure National Registry (ADHERE), which included 48,629 patients with acute HF, an association between BNP entry levels and intra-hospital mortality emerged. This relationship was independent of other clinical and laboratory parameters (such as age, gender, systolic blood pressure, heart rate, dyspnea at rest, sodium, creatinine, and urea levels), and the HFrEF vs. HFpEF status [19]. A systematic review of 19 studies revealed that the relative risk of allcause death increases by $35 \%$ for each $100 \mathrm{ng} / \mathrm{L}$ increase in admission BNP (21). Similarly, NT-proBNP can predict the short- and long-term prognosis in patients with acute $\operatorname{HF}[14,20]$.
Table 3 Natriuretic peptides cutoffs for acute heart failure diagnosis

\begin{tabular}{|c|c|c|c|c|c|}
\hline & $\mathrm{BNP}(\mathrm{ng} / \mathrm{L})$ & \multicolumn{3}{|c|}{ NT-proBNP (ng/L) } & $\begin{array}{l}\text { MR- } \\
\text { proANP } \\
\text { (ng/L) }\end{array}$ \\
\hline Heart failure unlikely & $<35$ & & $<125$ & & \\
\hline "Grey area" & $35-150$ & & $125-600$ & & \\
\hline Heart failure likely & $>150$ & & $>600$ & & \\
\hline Acute heart failure & & Age $<50$ & Age $50-75$ & Age $>75$ & \\
\hline Heart failure unlikely & $<100$ & $<300$ & $<300$ & $<300$ & $<120$ \\
\hline "Grey area" & $100-400$ & $300-450$ & $300-900$ & $300-1800$ & \\
\hline Heart failure likely & $>400$ & $>450$ & $>900$ & $>1800$ & \\
\hline
\end{tabular}

$B N P$ brain natriuretic peptide, $M R$-proANP mid-regional pro-atrial natriuretic peptide, $N T$-proBNP N-terminal pro-B-type natriuretic peptide 
Discharge NPs seem more effective than admission values for risk stratification, as demonstrated in an analysis of 7039 patients with acute HF enrolled in the Organized Program to Initiate Lifesaving Treatment in Hospitalized Patients with Heart Failure (OPTIMIZE-HF), where discharge BNP was more predictive of 1-year death (hazard ratio [HR] 1.34 [95\% confidence interval, 1.28-1.40]) and 1-year death or hospitalization (HR 1.15 [1.12-1.18]) than admission BNP [21]. ACC/AHA guidelines recommend BNP or NT-proBNP measurement on admission (class I, LOE A) and before discharge (class IIa, LOE B) for risk stratification [17].

The variation in NP levels from admission to discharge is also useful for risk prediction. In a study on 241 patients, a $<50 \%$ reduction in NT-proBNP predicted a higher risk of death or hospitalization at 1 year than a $\geq 50 \%$ reduction (HR 1.57 [1.08-2.28]), regardless of admission NT-proBNP, duration of hospital stay, and admission LVEF [22]. Even changes in NP concentrations over a few days have prognostic value: for example, $a \geq 30 \%$ BNP reduction within 5 days of initiation of inotropic support predicted all-cause mortality at 1 and 3 months [23].

In chronic HF, both BNP and NT-proBNP are important outcome predictors. In a sub-analysis of the Valsartan Heart Failure Trial (Val-HeFT) study, baseline NT-proBNP was a stronger predictor of mortality or HF hospitalization than BNP [24]. A study of 2364 patients with chronic HF found that baseline NT-proBNP predicts mortality at 1 and 5 years also in individuals aged $>77$ years and those aged $>85$ years, with higher cutoffs than in the general population [25]. Even in chronic HF, NP changes are more effective outcome predictors than individual values, as evidenced by another subanalysis of the Val-HeFT study, where NT-proBNP changes at 4 months were more predictive of all-cause death than baseline values [26]. Several studies also showed that the NP changes over time are associated with LV remodelling [27]. For example, a sub-analysis of the Guiding Evidence Based Therapy Using Biomarker Intensified Treatment (GUIDEIT) study found that, after HF therapy optimization, LVEF improved and LV volumes decreased proportionally to NTproBNP decrease [28].

\section{Screening of heart failure}

In an analysis of 3346 subjects without clinical evidence of HF followed for an average of 5 years, baseline BNP or NT-proBNP $>80$ th percentile were associated with a significantly higher risk of new-onset HF (BNP: HR 3.07 [1.51-6.26], $p=0.002$; NT-proBNP: HR 5.02 [2.32-10.85], $p<0.001$ ) [29]. Similarly, in a sub-analysis of the Prevention of Events With Angiotensin-Converting Enzyme Inhibition (PEACE) study on 3761 subjects with stable coronary artery disease and preserved LVEF, BNP, and NT-proBNP were strong predictors of HF development during a median 5 -year follow-up [30]. Dynamic changes in NPs are effective in predicting HF onset. In the Cardiovascular Health Study (CHS), NT-proBNP values were dosed at baseline and 2-3 years later in 2975 elderly subjects with no evidence of HF. After a median 12-year follow-up, among subjects with baseline NT-proBNP $<190 \mathrm{ng} / \mathrm{L}$, those who showed a biomarker increase $>25 \%$ between the two measurements had a higher risk of developing HF (HR 2.13 [1.68-2.71]) or die of cardiovascular causes (HR 1.91 [1.43-2.53]) compared to those with stable NT-proBNP values [31]. Similarly, in the group of subjects with baseline NT-proBNP $\geq 190 \mathrm{ng} / \mathrm{L}$, those where NT-proBNP levels increased $>25 \%$ were at a higher risk of HF (HR 2.06 [1.56-2.72]) or cardiovascular death (HR 1.88 [1.37-2.57]) [31].

Two randomized controlled trials investigated the possibility of preventing HF development through a followup and therapy choices based on NP levels. In the study St. Vincent's Screening to Prevent Heart Failure (STOPHF), 1374 subjects aged $>40$ years and with at least one risk factor (hypertension, dyslipidemia, obesity, vascular disease, diabetes mellitus) or cardiovascular comorbidity (moderate-to-severe valve disease, arrhythmia requiring intervention) were randomized to a follow-up by the general practitioner or to a cardiological evaluation with echocardiography whenever BNP was $>50 \mathrm{ng} / \mathrm{L}$. After an average of 4 years, significantly fewer subjects belonging to the second group had reached the primary endpoint of LV dysfunction with or without HF symptoms (odds ratio (OR) 0.55 [0.37-0.82], $p=0.003$ ). This result is partly explained by an increased prescription of RAAS inhibitors $(56.5 \%$ vs. $49.6 \%, p=0.001)$ in subjects with BNP-driven follow-up and, possibly, by an increased adherence to therapy and lifestyle recommendations [32]. Similarly, in the NT-proBNP Guided Primary Prevention of CV Events in Diabetic Patients (PONTIAC) study, enrolling 300 patients with type 2 diabetes and NT-proBNP $>125 \mathrm{ng} / \mathrm{L}$ with no structural heart disease, a strategy based on rapid titration of RAAS inhibitors and beta-blockers significantly reduced the primary endpoint of hospitalization or death from cardiovascular causes at 2 years (HR 0.35 [0.13-0.98], $p=0.04$ ) compared to standard follow-up [33]. Based on this evidence, ACC/ AHA guidelines suggest that NPs should be used to screen subjects at risk of developing HF to optimise medical therapy and prevent LV dysfunction (class IIa, LOE B). Nonetheless, proposing a standardised biomarker-driven screening and intervention strategy is difficult due to the heterogeneous definition of "individuals at risk" in the different studies [17]. 


\section{Guide to therapy}

Guideline-recommended HF therapies tend to reduce NP levels, and changes in plasma NPs may be used as surrogate end-points to assess the efficacy of new HF therapies [34] Despite these premises, the use of NPs to guide HF therapy is still under discussion. Murdoch et al. were the first to propose an optimization of HF therapy driven by NPs. In a trial of 22 patients with chronic HF randomized to ACE-inhibitor titration guided by serial BNP measurements or empirical titration, the first approach resulted in a greater reduction in heart rate and BNP values as well as an increase in plasma renin activity after 8 weeks, reflecting a more intensive RAAS inhibition [35]. Afterwards, several small randomized controlled trials tested whether a titration strategy guided by BNP or NT-proBNP was superior to the standard of care, with positive results in some trials and neutral results in others [34]. Meta-analyses on these studies showed that a NP-guided treatment is associated with lower rates of all-cause mortality and HF hospitalization [36-38]. In the GUIDE-IT trial, 1100 patients with $\mathrm{LVEF}<40 \%$, a previous $\mathrm{HF}$ episode during the last 12 months and BNP $>400 \mathrm{ng} / \mathrm{L}$ or NT-proBNP $>2000 \mathrm{ng} / \mathrm{L}$ in the previous 3 months were randomized to a titration strategy guided by NT-proBNP (target NT-proBNP $<1000 \mathrm{ng} / \mathrm{L}$ ) or the standard of care. The study was discontinued for futility after the enrolment of 894 patients, with a median follow-up of 15 months, because of no difference in the primary endpoint (cardiovascular death or HF hospitalization: HR 0.98 [0.79-1.22], $p=0.88$ ). None of the secondary endpoints (individual components of the primary endpoint, all-cause death, HF hospitalizations, days to hospitalization for cardiovascular causes, adverse events) differed significantly between the two groups [39]. Furthermore, NT-proBNP-driven management did not reduce healthcare costs nor improved the quality of life [40]. However, the percentage of subjects who had reached the target of NT-proBNP $<1000 \mathrm{ng} / \mathrm{L}$ and the percentage of subjects on optimal medical therapy did not differ significantly between groups, differently from other studies, suggesting a greater therapeutic effort in the control group as well [39]. These results support the notion that we should not using NPs as an "intellectual crutch to remind physicians to practice optimal medicine" [41].

\section{MR-proANP}

Plasma ANP increases in HF in response to the stretching of atrial cardiomyocytes. The dosage of ANP is complicated by its short half-life (2-5 min) because of rapid cleavage by neprilysin. Its precursor (proANP), produced equimolarly to ANP, has a longer half-life, and there is a reliable assay that measures its mid-regional portion (MR-proANP) [11]. In the study Biomarkers in Acute Heart Failure (BACH), MR-proANP was non-inferior to BNP to diagnose acute HF in subjects with new-onset dyspnoea (cutoff $\geq 120 \mathrm{pmol} / \mathrm{L}$; sensitivity $97 \%$, specificity $60 \%$, accuracy $74 \%$ ) [42]. Similarly, MR-proANP showed an only slightly lower performance than NT-proBNP to diagnose acute HF in the PRIDE study (AUC 0.90 vs. $0.94, p=0.001$ ) [43]. In both studies, MR-proBNP had an additive diagnostic value over BNP or NT-proBNP [42, 43]. ESC guidelines recommend the use of MR-proANP (as an alternative to BNP or NT-proBNP) for discrimination of acute $\mathrm{HF}$ from non-cardiogenic causes of dyspnoea (class I, LOE A) [2].

Several studies have also demonstrated a role of MRproBNP in predicting death risk in acute [43] and chronic $[44,45] \mathrm{HF}$, independently of NT-proBNP. A high degree of correlation between MR-proANP and NT-proBNP was reported, such as $r=0.80$ in a study by von Healing et al. [44].

\section{Factors affecting NP values}

$\mathrm{NP}$ values can be affected by age, gender, ethnicity and genetic variants, and also by numerous cardiac and noncardiac disorders (Table 4).

NP levels are slightly higher in women than men in age-matched healthy individuals [46], perhaps because of

Table 4 Main confounding factors in the clinical interpretation of natriuretic peptides

Factors that increase natriuretic peptides concentrations Factors that decrease natriuretic peptides concentrations

Advanced age

Neprilysin inhibitor therapy*

Kidney disease

Cardiotoxic drugs

Acute coronary syndrome

Right ventricular dysfunction

Pulmonary hypertension

Pulmonary embolism

Arrhythmias (atrial fibrillation)

Anemia/conditions with hyperdynamic circulation (sepsis, hyperthyroidism)
Obesity

Acute (flash) pulmonary oedema

Constrictive pericarditis

Cardiac tamponade

* Only for brain natriuretic peptide (BNP) 
an effect of sexual hormones [47]. This difference is also found in HF patients, being more evident in HFrEF than in HFpEF [48].

NT-proBNP levels tend to be lower in black individuals. In the Dallas Heart study, which included 3148 individuals (51\% Black, $31 \%$ White, $18 \%$ Hispanic) without major cardiovascular diseases (myocardial infarction, HF, or stroke), median NT-proBNP levels were significantly lower $(p<0.0001)$ in Black subjects $(24$ [10-52] $\mathrm{ng} / \mathrm{L}$ ) compared to Hispanics (30 [14-59] ng/L) and Whites (32 [16-62] ng/L) [49]. Interestingly, Blacks showed also a higher prevalence of hypertension and a higher LV mass index, which might be a consequence of their relative NP "deficiency" [49]. In another multicentric study on 92,072 patients hospitalized for HF, median BNP concentration on admission was found to be higher in Asian (1066 ng/L) and Black (866 ng/L) patients than in Whites (776 ng/L) and Hispanics (737 ng/L); nonetheless, increased BNP levels were predictive of higher inhospital mortality and hospital length of stay irrespective of ethnicity [50].

Genetic polymorphisms can also influence NP levels. Among 11,361 subjects enrolled in the Atherosclerosis Risk in Communities (ARIC) prospective cohort study, carriers of the rs198389 GG genotype (a functional variant in the promoter region of $N P P B$ ) showed $41 \%$ higher mean plasma NT-proBNP concentration compared with the AA genotype, with intermediate values in heterozygotes; this difference was independent of Black or White ethnicity [51]. Notably, carriers of the GG allele had also lower incidence of hypertension, and, after a median follow-up of 23 years, showed a lower cardiovascular mortality and longer life expectancy than carriers of the AA variant [51]. Similarly, individuals with the NPPA polymorphisms rs5068 or rs198358 have increased circulating levels of NPs, and a 15\% reduced risk of developing hypertension [52].

Subjects with a glomerular filtration rate (GFR) $<60 \mathrm{~mL} /$ $\min / 1.73 \mathrm{~m}^{2}$ tend to have higher NPs because of a reduction in renal clearance and cardiac damage secondary to CKD. Therefore, in patients with GFR $<60 \mathrm{~mL} / \mathrm{min} / 1.73 \mathrm{~m}^{2}$, the use of a higher BNP cutoff ( $200 \mathrm{ng} / \mathrm{L})$ has been proposed [53]. Conversely, the adoption of age-stratified NT-proBNP cutoffs is sufficient given the correlation between age and the degree of renal dysfunction [18].

Arrhythmias, particularly atrial fibrillation, may cause a paroxysmal or sustained increase in plasma NP levels due to a release of NPs by atrial cardiomyocytes [18]. Increased wall stress is the mechanism underlying NP release in hyperdynamic conditions (such as anemia, sepsis, and hyperthyroidism), as well as in acute coronary syndromes, pulmonary hypertension, and right ventricular dysfunction [18].
Neprilysin is an enzyme degrading BNP. Neprilysin inhibitors such as sacubitril (used in combination with valsartan in subjects with $\mathrm{HFrEF}$ ) tend to transiently increase BNP levels after the start of treatment, while NT-proBNP is not affected by this mechanism and tends to decrease in response to sacubitril/valsartan therapy. Therefore, NTproBNP is the biomarker of choice in patients receiving sacubitril/valsartan [18, 54].

NP levels are lower in obese than non-obese subjects regardless of whether HF is present or not. This might depend from a number of factors, including reduced NP release, and different kinetics of circulating NPs. The use of $50 \%$ lower BNP and NT-proBNP cutoffs has been proposed to diagnose HF [18]. These biomarkers retain a prognostic role in obese HF patients, although their prognostic performance seems lower than other biomarkers such as highsensitivity troponin $\mathrm{T}$ (hs-TnT) and soluble suppression of tumorigenesis-2 (sST2) [18, 55].

Patients with cardiac tamponade, constrictive pericarditis, or acute pulmonary edema have sometimes disproportionately low NPs compared to their symptoms. This is due to the absence of a marked increase in LV wall stress in these acute conditions and/or the rapid clinical deterioration with little time for NP production and release [18].

\section{Biomarkers of neurohormonal activation}

Figure 2 and Table 5 provide an overview of HF biomarkers on the basis of the relevant pathophysiological pathway, according to the classification proposed by Braunwald in 2008 [56].

\section{Norepinephrine and chromogranin}

In 1984, Cohn et al. reported that plasma norepinephrine was a good outcome predictor in HF [57]. This was confirmed in early HF drug trials [58], while a more recent study showed that norepinephrine did not refine risk prediction over a model including the Seattle Heart Failure Model and BNP [59]. In addition to catecholamines, secretory granules of neuroendocrine cells contain chromogranin A and B, whose production increases proportionally to $\mathrm{HF}$ severity $[60,61]$. In a small study, chromogranin A emerged as a good predictor of mortality in patients with chronic HF [60].

\section{PRA}

In a study of 996 patients with chronic HF, plasma renin activity (PRA) predicted cardiac death independently from NT-proBNP and LVEF [62]. In the Aliskiren Trial on Acute 


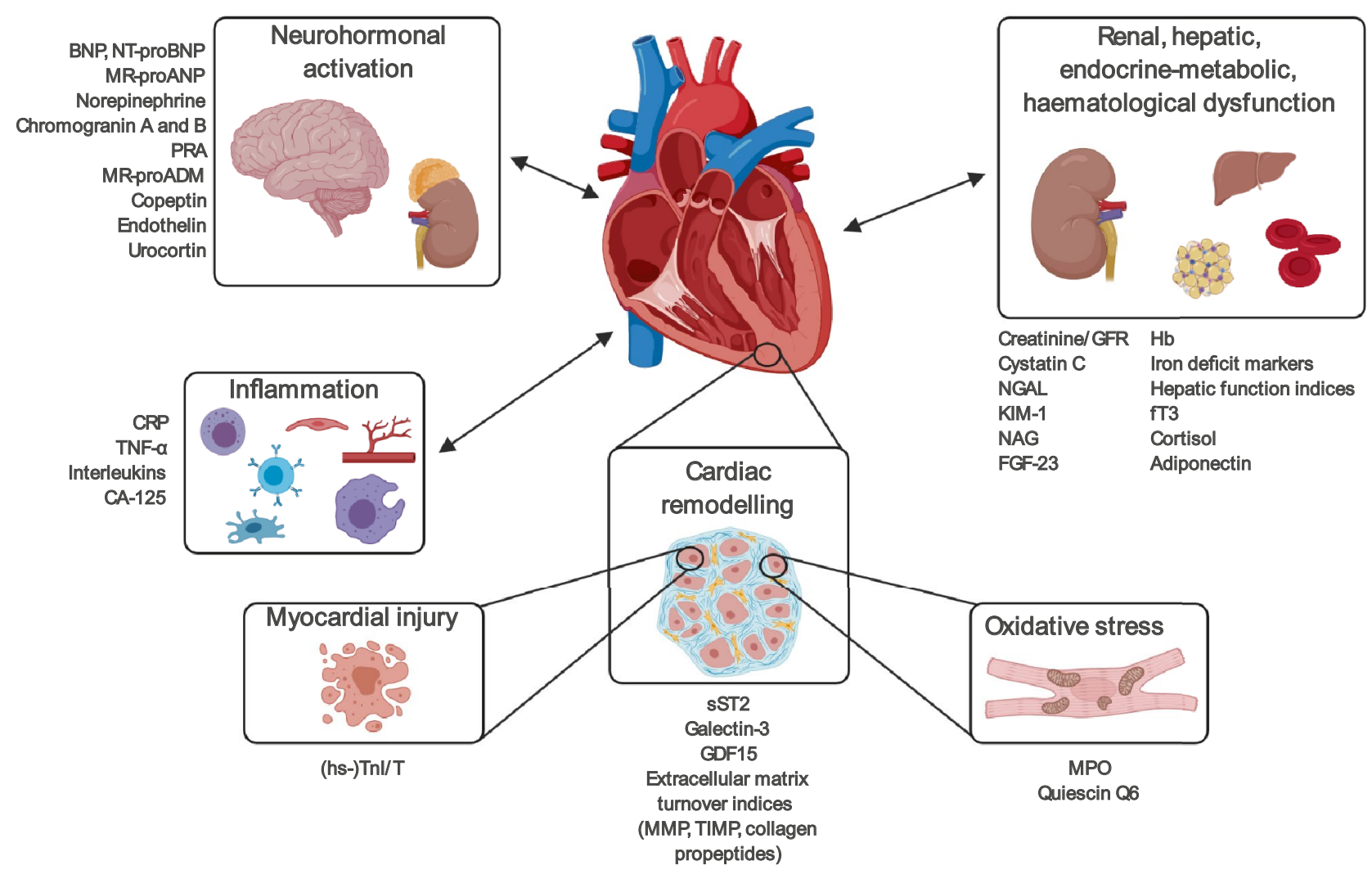

Fig. 2 Main pathophysiological pathways involved in heart failure and their most representative biomarkers. BNP brain natriuretic peptide, CA125 cancer antigen 125, CRP C-reactive protein, FGF-23 fibroblast growth factor-23, fT3 triiodothyronine, GDF15 growth differentiation factor, GFR glomerular filtration rate, hs-TnI/T high sensitivity-troponin I/T, KIM-1 kidney injury molecule-1, MMP matrix metalloproteases, MPO myeloperoxidase, MR-proADM mid-regional

Heart Failure Outcomes (ASTRONAUT) study, low baseline PRA predicted mortality and HF hospitalisation. In this study, PRA reduction during therapy with aliskiren, a direct renin inhibitor, did not predict a better outcome [63].

\section{ADM}

Adrenomedullin (ADM) is a hormone synthesized by almost all tissues, but mainly by the adrenal medulla, heart, lungs, and kidneys, in response to volume or pressure overload. ADM has vasodilatory, natriuretic, inotropic, and cardioprotective effects [64]. Plasma ADM increases in HF, but its dosage is complicated by its short half-life and binding to carrier proteins. A fragment of its precursor, the midregional pro-ADM (MR-proADM), is more easily dosed and has been tested as a prognostic marker of HF [64]. In the BACH study, MR-proADM was a better predictor of 90-day survival than BNP in acute HF (accuracy $74 \%$ vs. pro-adrenomedullin, MR-proANP mid-regional pro-atrial natriuretic peptide, NAG N-acetyl- $\beta$-(D)-glucosaminidase, NGAL neutrophil gelatinase-associated lipocalin, NT-proBNP N-terminal pro-B-type natriuretic peptide, PRA plasma renin activity, sST2 soluble suppression of tumorigenesis-2, TIMP tissue inhibitor of metalloproteinase, TNF- $\alpha$ tumor necrosis factor alpha

$62 \%, p<0.001$ ) [42]. This was confirmed in a sub-analysis of the PRIDE study, where MR-proADM was the best predictor of 1-year death, while MR-proANP and NT-proBNP showed a better prognostic performance after 1 year from the diagnosis of acute HF [43]. In 297 patients with chronic HF included in the Australia-New Zealand Heart Failure Study, MR-proADM above the median predicted an increased risk of death (relative risk [RR] 3.92 [1.76-8.7]) and HF hospitalization (RR 2.4 [1.3-4.5]) at 1.5 years, regardless of clinical and echocardiographic parameters [65]. In another study on 501 patients with chronic HF, MR-proADM was a good predictor of 1-year survival with a similar AUC than NT-proBNP $(p=0.3)$ [66]. Although these data support the use of MR-proADM as a prognostic marker, at least for short-term risk stratification, there are some limitations that prevent its use in the clinical practice. Indeed, MR-proADM is not a cardiac specific biomarker, since it is expressed at multiple sites in the body, and factors that may influence its interpretation are yet to be fully characterized. 
Table 5 Heart failure biomarkers

\begin{tabular}{|c|c|}
\hline \multicolumn{2}{|l|}{ Neurohormonal activation } \\
\hline $\begin{array}{l}\text { Natriuretic peptides (BNP, NT-proBNP, ANP, } M R \text { - } \\
\text { proANP) } \\
\text { Norepinephrine } \\
\text { Chromogranin A and B } \\
\text { Renin/PRA } \\
\text { Angiotensin II } \\
\text { Aldosterone } \\
\text { Adrenomedullin/MR-proADM }\end{array}$ & $\begin{array}{l}\text { Vasopressin/copeptin } \\
\text { Endothelin (ET-1, big ET-1, CT-proET-1) } \\
\text { Urocortin } \\
\text { Neprilysin } \\
\text { Neuregulin } \\
\text { CD146 }\end{array}$ \\
\hline Myocardial injury & \\
\hline $\begin{array}{l}(h s-) T n T / I \\
\text { CK-MB } \\
\text { Myosin light chain } 1 \\
\text { hFABP }\end{array}$ & $\begin{array}{l}\text { HSP-60 } \\
\text { sFAS } \\
\text { sTRAIL }\end{array}$ \\
\hline Cardiac remodelling & \\
\hline $\begin{array}{l}\text { sST2 } \\
\text { Galectin-3 } \\
\text { GDF15 } \\
\operatorname{MMP}(2,3,4,8,9) \\
\operatorname{TIMP}(1,4) \\
\text { Collagen propeptides (PIIINP, ICTP) }\end{array}$ & $\begin{array}{l}\text { Myostatin } \\
\text { Syndecan-4 } \\
\text { Osteopontin } \\
\text { IGFBP7 } \\
\alpha 1 \text {-antitrypsin }\end{array}$ \\
\hline Inflammation & \\
\hline $\begin{array}{l}\text { CRP } \\
\text { TNF- } \alpha \\
\text { Interleukin }(1,2,6,8,10,18) \\
\text { CA-125 } \\
\text { Procalcitonin } \\
\text { LP-PLA }_{2} \\
\text { TWEAK } \\
\text { Fas/APO-1 } \\
\text { Osteoprotegerin }\end{array}$ & $\begin{array}{l}\text { sTNFR-1 and -2 } \\
\text { YKL-40 } \\
\text { IL-1RA } \\
\text { LRG } \\
\text { Soluble endoglin } \\
\text { Serin protease PR3 } \\
\text { Complex S100A8/A9 } \\
\text { Pentraxin-3 } \\
\text { Midkine }\end{array}$ \\
\hline Oxidative stress & \\
\hline $\begin{array}{l}\text { MPO } \\
\text { Quiescin Q6 } \\
\text { Oxidized LDL } \\
\text { Urinary biopyrrins }\end{array}$ & $\begin{array}{l}\text { Urinary and plasmatic isoprostanes } \\
\text { Urinary 8-OHdG } \\
\text { Plasmatic malondialdehyde }\end{array}$ \\
\hline Comorbidity & \\
\hline $\begin{array}{l}\text { Renal function and injury } \\
\text { Creatinine/GFR } \\
\text { Plasma albumin, albuminuria } \\
\text { Urinary albumin/creatinine ratio } \\
\text { Cystatin } C \\
N G A L \\
\text { KIM-1 } \\
N A G \\
F G F-23 \\
\beta \text {-trace protein } \\
\beta 2 \text {-microglobulin } \\
\text { Hepatic function } \\
\text { AST, ALT } \\
\text { GGT } \\
\text { Bilirubin } \\
\text { miRNA }\end{array}$ & $\begin{array}{l}\text { Hematological parameters } \\
\text { Hemoglobin } \\
\text { Iron deficiency (ferritin, transferrin saturation) } \\
\text { RDW } \\
\text { Endocrine-metabolic changes } \\
\text { fT3, fT4, TSH } \\
\text { Cortisol } \\
\text { Adiponectin } \\
\text { Orexin } \\
\text { Leptin } \\
\text { Resistin } \\
\text { IGF-1, GH }\end{array}$ \\
\hline
\end{tabular}

The biomarkers underlined are those most studied in heart failure and whose role has been thoroughly discussed in the text. ALT, alanine aminotransferase; ANP, atrial natriuretic peptide; APO-1; apoptosis 1 antigen; AST, aspartate aminotransferase; BNP, brain natriuretic peptide; CA-125, cancer antigen 125; CK-MB, creatin kinase MB; CRP, C-reactive protein; CT-proET-1, C-terminal proendothelin-1; ET-1, endothelin-1; FGF-23, fibroblast growth factor 23; fT3, triiodothyronine; fT4, thyroxine; GDF15, growth differentiation factor; GFR, glomerular filtration rate; GGT, gamma-glutamyl transferase; GH, growth hormone; hFABP, heart-type fatty acid binding protein; HSP-60, thermal shock protein 60; hs-TnI/T, high-sensitivity-troponin I/T; ICTP, collagen C-telopeptide type I; IGFBP7, insulin-like growth factor binding protein-7; IGF-1, insulin-like growth factor 1; IL-1RA, interleukin receptor antagonist 1; KIM-1, renal injury 
Table 5 (continued)

molecule 1; LP-PLA 2 , lipoprotein-associated phospholipase A2; LRG, leucine-rich alpha 2 glycoprotein; miRNA, microRNA; MMP, matrix metalloproteinase; MPO, myeloperoxidase; MR-proADM, mid-regional pro-adrenomedullin; MR-proANP, mid-regional pro-atrial natriuretic peptide; NAG, N-acetyl- $\beta$-(D)glucosaminidase; NGAL, neutrophil gelatinase-associated lipocalin; NT-proBNP, N-terminal pro-B-type natriuretic peptide; 8-OHdG, 8-hydroxy-2'-deoxyguanosin; PIIINP, procollagen peptide type III-N-terminal; PRA, plasma renin activity; RDW, red blood cell distribution width; sFAS, soluble fragment stimulating apoptosis; sST2, soluble suppression of tumorigenesis-2; sTRAIL, soluble tumour necrosis factorrelated apoptosis-inducing ligand; TIMP, tissue inhibitor of metalloproteinase; sTNFR, soluble tumour necrosis factor alpha receptor; TNF- $\alpha$, tumour necrosis factor alpha; TSH, thyroid stimulating hormone; TWEAK, tumour necrosis factor-like weak inducer of apoptosis; YKL-40, chitinase-3-like protein 1

\section{Copeptin}

Vasopressin is a hormone with antidiuretic and vasoconstrictive activities released by the hypothalamus in response to hyperosmolarity or hypovolemia [67]. In $\mathrm{HF}$, vasopressin is disproportionately increased because of increased baroreceptor stimulation due to a reduced cardiac output simulating a hypovolemic state [67]. The C-terminal fragment of pro-vasopressin is named copeptin, and is more easily dosed than vasopressin [68]. In the BACH study, patients with elevated copeptin had greater lung and peripheral congestion and higher 3-month mortality (HR 3.85 [1.83-8.09]; $p<0.001$ ), especially those with hyponatraemia [68]. In a meta-analysis of 4473 patients with acute and chronic HF, copeptin was a good predictor of death from all causes (RR 2.64 [2.09-3.32]), with a similar performance than NT-proBNP [69].

\section{ET-1}

Endothelin-1 (ET-1) is produced by the vascular endothelium in response to shear stress, neuronal stimulation, and inflammation. ET-1 exerts vasoconstrictive, proinflammatory, prooxidative actions and promotes cardiac remodelling. The endothelium releases a precursor, big ET-1, whose C-terminal fragment is then cleaved [70]. In a sub-analysis of the Acute Study of Clinical Effectiveness of Nesiritide in Decompensated Heart Failure (ASCEND-HF), baseline ET-1 correlated with adverse events during hospitalization and 3-month death in patients hospitalized for acute HF, with an additive prognostic value over NT-proBNP [71]. In 115 patients with chronic HF, ET-1 improved the prognostic performance of a model including clinical variables and other biomarkers such as NT-proBNP, hs-TnI, and sST2 [72]. The percentage of time spent with ET- $1 \leq 5.9 \mathrm{pg} / \mathrm{mL}$ (corresponding to the 75 th percentile) predicted a lower rate of cardiovascular events (odds ratio [OR] 0.75 [0.62-0.91]). Similarly, patients with a reduction in ET-1 over time had a better outcome [72].

\section{Urocortin-1}

Urocortin-1 is a member of the corticotropin-releasing factor family. It is mainly produced in the central nervous system, but also in the heart and other tissues including. Urocortin-1 has vasodilating, inotropic, and cardioprotective effects [73]. Plasma urocortin-1 increases in HF, but this biomarker does not appear to have any additional diagnostic or prognostic value to NT-proBNP [73].

\section{Biomarkers of cardiac damage}

\section{Cardiac troponins}

Elevated cardiac troponins ( $\mathrm{TnT}$ and $\mathrm{TnI}$ ) are observed in the majority of patients with acute or chronic HF, especially when measured through high-sensitivity assays. Elevated troponin levels mainly reflect the progressive death of cardiomyocytes, but chronic release of cytoplasmic vesicles (blebs) containing cellular material has also been demonstrated. Possible mechanisms are an imbalance between oxygen demand and supply, particularly in the subendocardial layers, and direct myocardial damage due to neurohormonal activation, inflammation and oxidative stress [74].

Troponins are very effective in prognostic stratification of acute HF. In a study of 144 patients with acute HF, more than $99 \%$ of patients had hs-TnI levels above the 99th percentile of the reference population. Furthermore, an hs$\mathrm{TnI}>23 \mathrm{ng} / \mathrm{L}$ was associated with an increased risk of hospitalisation or death, which was significantly higher in those with an increase in hs-TnI during hospitalization, compared to those in which hs-TnI remained stable or decreased over time [75]. In 202 patients with acute HF, Pascual-Figal et al. found hs-TnT above the 99th percentile in $81 \%$ of cases; hs$\mathrm{TnT}>20 \mathrm{ng} / \mathrm{L}$ identified patients with an increased risk of death [76]. Admission hs-TnT was predictive of intra-hospital mortality and at 6, 12, and 24 months in 1499 subjects hospitalized for acute $\mathrm{HF}$, albeit with a lower performance than NT-proBNP [77]. 
In 4053 subjects with chronic HF from the Val-HeFT, hs-TnT was measurable in $10 \%$ of cases with traditional dosages and $92 \%$ with high-sensitivity assays; hs-TnT was also predictive of all-cause death [78]. In an individual patient data meta-analysis on 9289 subjects with chronic HF, hs-TnT was predictive of all-cause death (HR 1.48 [1.41-1.55]), cardiovascular death (HR 1.40 [1.33-1.48]) and hospitalization for cardiovascular causes (HR 1.42 [1.36-1.49]) even when adjusting for age, gender, HF etiology, LVEF, GFR, and NTproBNP [79].

ACC/AHA guidelines recommend the dosage of hs-TnT/I on admission in patients hospitalized for HF or those with chronic HF (class I, LOE A) for the purpose of risk stratification [17]. Conversely, ESC guidelines recommend its use only on admission in patients with suspicion of acute $\mathrm{HF}$ within a laboratory analysis panel including full blood cell count, electrolytes, renal function, blood glucose, thyroid and liver function (class I, LOE C), with the main goal of excluding an acute coronary syndrome [2] (Table 2).

High-sensitivity assays allow to detect cardiac troponins in $50-80 \%$ of subjects from the general population, sometimes with values as high as $>99$ th percentile, particularly in subjects at risk of developing HF such as the elderly, patients with cardiovascular risk factors or established cardiac disease [74]. In a study on 2794 asymptomatic subjects with $>65$ years of age, hs-TnT $>13 \mathrm{ng} / \mathrm{L}$ were predictive of HF development (6.4\% [5.8-7.2] per 100 person-year; HR 2.48 [2.04-3.00]) and cardiovascular death (4.8\% [4.3-5.4] per 100 person-year; HR 2.91 [2.37-3.58]); moreover, an increase in hs-TnT $>50 \%$ predicted a worse prognosis (32). Similarly, a meta-analysis of 67,063 asymptomatic subjects showed that those with higher hs-TnI/T (highest vs. lowest tertile) have a greater risk of developing HF (hs-TnT: HR 2.11 [1.69-2.63]; hs-TnI: HR 2.09 [1.53-2.85]) [80].

\section{Myocardial remodelling, inflammation, and oxidative stress}

\section{sST2}

Suppression of tumorigenesis-2 ligand (ST2L) is a member of the Toll-like receptor family binding interleukin 33 (IL33) [81]. The IL-33/ST2L axis is mainly a signalling mechanism of the immune system, but has also anti-apoptotic, anti-fibrotic and anti-hypertrophic effects in the heart. sST2 acts as a decoy receptor for IL-33, thus blocking these positive effects. sST2 is mainly produced outside of the heart in response to haemodynamic overload, inflammation, and profibrotic stimuli, which are common in HF [81].

Being a non-cardio-specific marker, sST2 cannot be used to diagnose $\mathrm{HF}$, but it is helpful for risk stratification. A meta-analysis of 4835 patients with acute HF found that both admission and discharge sST2 were predictive of all-cause death (HR 2.46 [1.80-3.37] and 2.06 [1.37-3.11], respectively) and cardiovascular death (HR 2.29 [1.41-3.73] and 2.20 [1.48-3.25], respectively), and that discharge sST2 predicted rehospitalization for HF (HR 1.54 [1.03-2.32]) [82]. Repeating sST2 measurements during HF hospitalization is important, as demonstrated in a study on 150 patients with acute HF, where the percent change in sST2 during hospitalization was predictive of 3-month death regardless of BNP or NT-proBNP [83]. Similar results were found by the Translational Initiative on Unique and novel strategies for Management of Patients with Heart failure (TRIUMPH) cohort study on 496 patients with acute HF with 7 measurements during 1 year of follow-up. Baseline sST2 was predictive of all-cause death or HF hospitalization (HR for each standard deviation increase of $\log _{2}$ (ST2): 1.30 [1.08-1.56]), and changes in sST2 across repeated measurements were even more predictive (HR for each standard deviation increase of the log value ${ }_{2}$ (ST2): 1.85 [1.02-3.33]), independent from serial NT-proBNP [84].

sST2 has an important role in risk stratification of chronic HF patients, as demonstrated by numerous studies and confirmed in a meta-analysis by our group [85]. The prognostic value of sST2 in chronic HF is independent from NTproBNP and hs-TnT [85] and is less influenced by age than the other two biomarkers [86]. sST2 has a similar prognostic performance in HFrEF and HFpEF, and is superior to galectin-3 [81]. Additionally, sST2 independently predicts reverse remodelling and has been included in the ST2-R2 score, which includes sST $<48 \mathrm{ng} / \mathrm{mL}$ ( 3 points), non-ischemic etiology (5 points), absence of left branch block (4 points), $\mathrm{HF}$ duration $<1$ year ( 2 points), $\mathrm{LVEF}<24 \%$ ( 1 point) and treatment with beta-blockers (2 points) [81].

ACC/AHA guidelines recommend sST2 measurement for prognostic evaluation of patients with chronic HF [17] (Table 2), while ESC guidelines state that there is not enough evidence to recommend its use in clinical practice [2].

There is still no unanimous consensus on what is the best prognostic cutoff of sST2 in chronic HF. The most commonly used cutoff is $35 \mathrm{ng} / \mathrm{mL}$, while we proposed the value of $28 \mathrm{ng} / \mathrm{mL}$ based on an individual patient data meta-analysis [87]. Higher cutoff values have been proposed for risk stratification in acute HF [87].

\section{Galectin-3}

Galectin-3 is a lectin produced by macrophages involved in tissue and fibrous remodelling [88]. Although overexpressed in HF, galectin-3 is not useful to diagnose acute HF. Instead, galectin-3 is a good predictor of re-hospitalization for $\mathrm{HF}$ within 1 to 4 months, as demonstrated by a meta-analysis on 902 patients with acute HF [89]. In the GALectin-3 in Acute heart failure (GALA) study, galectin-3 measured on 
admission was a good predictor of 30-day mortality, but not of 1-year mortality [90]. However, sub-analyses of recent trials such as RELAXin in Acute Heart Failure (RELAXAHF) and ProBNP Outpatient Tailored Chronic Heart Failure (PROTECT) did not find a predictive value for 6-month death [91].

The prognostic performance of galectin-3 in HFrEF and HFpEF is lower than other molecules such as NT-proBNP or sST2, and largely influenced by renal function [91]. Nonetheless, ACC/AHA guidelines recommend the dosage of galectin-3 for prognostic stratification of patients with chronic HF, with the same LOE than SST2 [17] (Table 2). ESC guidelines do not recommend its use in clinical practice due to the absence of strong evidence [2].

\section{GDF-15}

Growth differentiation factor-15 (GDF-15) is expressed by numerous cell types, including cardiomyocytes, smooth and endothelial muscle cells, when exposed to several stressors. GDF-15 exerts anti-inflammatory and anti-apoptotic effects. Although it is not a cardiac-specific marker, the increase in plasma GDF-15 seems to have a prognostic role in HF [74]. In a sub-analysis of RELAX-AHF, GDF-15 elevation during a HF hospitalization, but not the admission value, was predictive of cardiovascular death at 180 days or a composite of cardiovascular death, HF hospitalization or kidney failure at 60 days [92]. In a study of 455 patients with chronic HF (median follow-up of 40 months), GDF-15 predicted mortality independent of clinical and laboratory variables including NT-proBNP (HR for an increase of 1 unit in the natural logarithm scale: 2.26 [1.52-3.37]) [93]. Accordingly, a post hoc analysis of Val-HeFT showed that the variation of GDF-15 over 1 year remained an independent predictor of death (HR for changes in GDF-15 at 12 months as a continuous variable: 1.01 [1.00-1.02]), even when accounting for clinical variables, BNP, CRP, hs-TnT, and their changes over time [94]. Unlike NT-proBNP, GDF-15 is not affected by atrial fibrillation, so this biomarker could be particularly useful in these patients [95].

\section{ECM}

The normal turnover of the extracellular matrix (ECM) depends on a balance between the activities of matrix metalloproteinases (MMPs) and their tissue inhibitors (TIMPs). This balance is altered in HF. MMP, TIMP, and many products of ECM degradation have been evaluated as diagnostic or prognostic biomarkers in HF [74]. The combination of increase in MMP-2, TIMP-4, procollagen type III-N-terminal peptide (PIIINP), and decrease in MMP-8 predicted the presence of HFpEF (AUC 0.79) [96]. Circulating levels of these molecules likely reflect the extent of myocardial remodelling, which in turn might be predictive of outcome. In a sub-analysis of the Randomized Aldactone Evaluation Study (RALES), PIIINP $>3.85 \mu \mathrm{g} / \mathrm{L}$ was predictive of adverse outcomes, and a reduction in PIIINP was observed only in patients on spironolactone, confirming the antifibrotic effect of this drug. In addition, the prognostic benefit of spironolactone therapy was significant only in subjects with high basal levels of collagen degradation products [97]. Similarly, in a sub-analysis of the Prospective Comparison of ARNI With ARB Global Outcomes in HF With Preserved Ejection Fraction (PARAGON-HF), treatment with sacubitril/valsartan led to a significant reduction of some degradation products such as TIMP-1 and PIIINP at a 16-month follow-up, compared to valsartan [98].

\section{Biomarkers of inflammation and oxidative stress}

Inflammation in HF may be triggered by direct cardiomyocyte damage (e.g., because of ischemia or pressure overload), or may reflect a systemic inflammatory state related to comorbidities. The latter mechanism seems crucial in HFpEF [99]. The first demonstration of a CRP elevation in HF dates back to 1956 [8]. Since then, numerous studies have investigated this association, highlighting the prognostic value of CRP, tumor necrosis factor alpha (TNF $\alpha$ ), and interleukin-6 (IL-6) in chronic HF [99]. The elevation of these 3 biomarkers has also been associated with an increased risk of HF development in elderly subjects [100, 101]. Recently, cancer antigen 125 (CA-125) has attracted some attention. CA-125 is a glycoprotein synthesized by mesothelial cells in response to increased hydrostatic pressure and/or inflammation. It is widely used as a biomarker for screening and prognostic stratification of many tumors, in particular ovarian cancer [102]. CA-125 levels correlate with signs and symptoms of congestion in HF, and a recent multicentre study in patients with worsening HF showed an association with mortality and risk of HF hospitalization at 1 year [102].

Mitochondrial dysfunction is typical of HF and leads to an increased production of reactive oxygen species (ROS) and a damage to cellular structures [99]. The inherent instability of ROS makes their measurement difficult. However, molecules that interact with ROS, including antioxidants, are good indicators of the oxidative status. The most interesting results in terms of risk stratification in HF have been obtained with myeloperoxidase (MPO) and, to a lesser extent, uric acid [99]. MPO is released by leukocytes as part of the inflammatory response. Plasma MPO increases in chronic HF and is associated with NYHA class and BNP [103]. In another study on 667 patients with acute dyspnea, MPO was equally high in subjects with non-cardiac and cardiac dyspnea, but predicted 1-year mortality regardless of BNP [104]. 


\section{Comorbidities}

\section{Kidney dysfunction}

Creatinine, azotaemia, and GFR are commonly used in clinical practice to monitor the effects of HF therapies, particularly diuretics. The same parameters are also useful prognostic markers. For example, a study by our group on 9289 patients with chronic HF showed that GFR had an additive prognostic value over NT-proBNP and hs-TnT [105]. It has been suggested that cystatin C, a protease cysteine inhibitor with ubiquitous expression whose clearance is entirely dependent on glomerular filtration, may be an outcome predictor in acute [106] and chronic [107] HF, independent from NPs and potentially superior to creatinine [107].

Cardiovascular and renal systems are functionally interconnected, which explains why indicators of renal damage have been evaluated as HF biomarkers. The most promising molecule is neutrophil gelatinase-associated lipocalin (NGAL), an iron-binding protein released by neutrophils and epithelial cells in response to acute renal damage and inflammation. In a study on 121 patients with acute HF, NGAL levels $>167.5 \mathrm{ng} / \mathrm{mL}$ ( 75 th percentile) were associated with a 2.7-fold higher risk of death and a 2.9-fold higher risk of death or hospitalization [108]. In chronic HF, kidney injury molecule-1 (KIM-1) and N-acetyl- $\beta$-(D)-glucosaminidase (NAG), two molecules expressed by proximal renal tubular cells, were associated with NYHA class and inversely correlated with LVEF. These molecules have been proposed as additional markers of cardio-renal syndrome and outcome in HF [109]. In a cohort of 2,130 patients of the Gruppo Italiano per lo Studio della Sopravvivenza nell'Insufficienza Cardiaca (GISSI-HF) study, NGAL, KIM-1, and NAG were independently associated with the combined endpoint of death or HF hospitalization, even in patients with normal renal function [110].

Fibroblast growth factor 23 (FGF-23) is expressed mainly by osteocytes and osteoblasts, and its main targets are the kidneys and parathyroids. FGF-23 was initially implicated in the progression of CKD, and seems to play a role in the development of cardiac hypertrophy and HF [111]. FGF-23 is expressed by cardiomyocytes and enhances RAAS activation through various mechanisms. FGF-23 could then provide a connection between kidney damage, altered bone mineral metabolism and cardiovascular remodelling [111]. FGF-23 levels are related to NYHA class and circulating NPs, and might hold prognostic significance in HFrEF or HFpEF [112].

\section{Liver dysfunction}

Liver dysfunction is common in advanced HF, mostly because of venous congestion due to right ventricular dysfunction. Elevation of transaminases and bilirubin and hypoalbuminemia are able to stratify the risk of patients with acute or chronic HF [113, 114].

\section{Iron deficiency}

Besides worsening HF symptoms, anemia is an established predictor of adverse outcome in patients with acute [115] or chronic HF [116]. Iron deficiency (defined as ferritin $<100 \mu \mathrm{g} / \mathrm{L}$ or $100-300 \mu \mathrm{g} / \mathrm{L}$ with transferrin saturation $<20 \%$ ) is very common in chronic HF (40-70\%), even in the absence of anemia, and predicts a worse prognosis (HR 1.42 [1.14-1.77]) independent from NYHA class, LVEF, kidney function, and NT-proBNP [117]. Randomized clinical trials have shown that correction of iron deficiency in patients with HFrEF improves exercise ability, symptoms, and quality of life [118].

\section{Endocrine and metabolic alterations}

Thyroid dysfunction can manifest itself as subclinical hypothyroidism or low T3 syndrome, is common in patients with chronic HF, and is associated with more severe symptoms and a worse prognosis $[119,120]$. Serum and salivary cortisol levels are often elevated in patients with chronic HF and have been associated with increased mortality [121, 122]. Adipokines are a class of hormones involved in regulating carbohydrate metabolism and fatty acids. Adiponectin, a protein secreted inversely proportional to the percentage of body fat, is the most studied so far in HF. Adiponectin increases in chronic HF and seems to predict a worse outcome $[123,124]$.

\section{Multi-marker strategies}

Multi-marker strategies reflecting different HF pathways could allow to better understand the disease phenotype of each individual patient, and possibly design a tailored therapy. For example, demonstrating an increase of a specific biomarker might prompt the start or up-titration of a therapy able to counteract the mechanisms leading to such elevation. Nonetheless, this approach has never been tested in randomized controlled trials.

Several studies have evaluated multi-marker scores for risk stratification in acute [125] and chronic HF (59), and for risk prediction of incident HF in the general population 
$[126,127]$. For example, we evaluated the measurement of NT-proBNP and hs-TnT with prognostic thresholds stratified by GFR for risk prediction in chronic HF [105]. Many other multi-marker strategies have been proposed [74, 128, 129]. In most studies, the biomarkers were arbitrarily selected. Conversely, in a recent sub-analysis of the Treatment of Preserved Cardiac Function Heart Failure With an Aldosterone Antagonist (TOPCAT) study, a machine-learning approach was pursued to generate a multi-marker panel (from 49 available analytes) able to predict a composite of all-cause death or HF hospitalization in patients with HFpEF [130].

Few biomarkers have shown an additive prognostic value to NPs. They include hs-TnI/T and sST2, and to a lesser extent galectin-3, GDF-15 and some markers of renal dysfunction [74]. ACC/AHA guidelines suggest that a combination of biomarkers (in particular NPs, sST2, galectin-3, and hs-TnI/T) may be more informative than individual biomarkers for risk stratification [17]. Finally, the integration of different biomarkers with clinical variables and imaging characteristics is an interesting, but largely unexplored, perspective.

\section{-Omics}

Several -omics exist: genomics, study of genes and their function; epigenomics, analysis of changes in the genetic code that influence their expression; transcriptomics, study of all RNA transcribed from a given genome; proteomics, evaluation of all proteins present in a cell or tissue; metabolomics, measurement of cellular metabolism products [131]. The main application of genetic testing in HF has been the identification of monogenic cardiomyopathies. In these cases, the identification of a culprit gene can influence therapeutic choices and lead to screening of family members. However, HF is most commonly the result of an interaction between genetic susceptibility and environmental exposure [131]. Genome-wide association studies have attempted to explore the association between specific single-nucleotide polymorphism (SNP) and the onset/progression of HF, with limited results [132]. Recent studies have also sought to identify epigenetic modifications potentially associated with HF development [133].

Transcriptomic studies have identified specific patterns of gene expression associated with different HF phenotypes (e.g., HFpEF vs. HFrEF) [134]. Many studies focused on the evaluation of microRNAs (miRNAs), short non-coding RNA able to influence gene expression at the post-transcriptional level. Several miRNAs are chemically stable and can be easily dosed in the plasma. Circulating levels of more than 30 miRNAs increase or decrease in patients with HF. miRNA panels seem able to accurately discriminate HFpEF from HFrEF [135]. However, strong evidence on the role of specific miRNAs for diagnosis, risk stratification or guide to treatment is currently lacking.
A proteomic approach showed that quiescin Q6, a protein involved in the formation of disulphide bonds, allows to discriminate acute HF from no-cardiac dyspnea [136]. Proteomic profiling has also been used to identify predictors of incident HF. For example, in a study including two community-based prospective cohorts of elderly individuals without HF, a proteomic analysis found that 9 proteins involved in apoptosis, inflammation, matrix remodelling, and fibrinolysis improved prediction of incident HF over a model including established risk factors (age, ethnicity, gender, heart rate, systolic blood pressure, anti-hypertensive medications, diabetes, coronary heart disease, smoking status, body mass index), but not when NT-proBNP was added to the model [137]. Moreover, Adamo et al. recently employed a proteomic approach to define proteomic signatures unique to specific HF phenotypes, such as HFrEF, HFpEF, and HFmrEF with improved or unchanged LVEF, ischemic and non-ischemic HF [138].

Some authors have employed metabolomic profiling to identify novel biomarkers or multi-marker panels associated with incident HF or HF prognosis [131]. Using a metabolomic approach, Hunter et al. found that plasma long-chain acylcarnitine concentration was significantly higher in HF patients compared to controls, and even discriminated HFrEF from HFpEF, being higher in HFrEF [139]. Another metabolomic study demonstrated that circulating long-chain acylcarnitine was independently associated with the risk for hospital readmission and mortality in chronic HF; in addition, long-chain acylcarnitine concentration decreased after LV assist device placement in a subgroup of patients with end-stage HF [140]. As for multi-marker approaches, in a study on 1,032 HFrEF patients, a 13-metabolite profile was defined and then validated as a predictor of mortality, improving survival models including established clinical risk factors and even NPs [141].

\section{Conclusions}

BNP and NT-proBNP are the gold standard in prognostic diagnosis and stratification of $\mathrm{HF}$ and their use is recommended by both ESC and ACC/AHA guidelines. NP measurement may allow to identify patients with subclinical LV dysfunction, thus allowing preventive measures to slow down the progression to clinical HF. The role of NPs as guides to treatment remains unclear. BNP and NT-proBNP have different diagnostic cutoffs, and NP concentrations should be interpreted on the light of many factors such as age, kidney function, arrhythmia, and obesity, among others. Other biomarkers can provide additional information to NPs. Many biomarkers have been evaluated, linked to specific mechanisms of neurohormonal activation, myocardial damage, cardiac remodelling, inflammation/oxidative 
stress, and comorbidities. High-sensitivity troponins and sST2 are currently the most promising biomarkers as additive tools to BNP and NT-proBNP for prognostic stratification of HF. Multi-marker panels or scores and the different -omic techniques represent other intriguing perspectives for future research.

Acknowledgements Open access funding provided by Scuola Superiore Sant'Anna within the CRUI-CARE Agreement.

\section{Declarations}

Conflict of interest The authors declare no competing interests.

Open Access This article is licensed under a Creative Commons Attribution 4.0 International License, which permits use, sharing, adaptation, distribution and reproduction in any medium or format, as long as you give appropriate credit to the original author(s) and the source, provide a link to the Creative Commons licence, and indicate if changes were made. The images or other third party material in this article are included in the article's Creative Commons licence, unless indicated otherwise in a credit line to the material. If material is not included in the article's Creative Commons licence and your intended use is not permitted by statutory regulation or exceeds the permitted use, you will need to obtain permission directly from the copyright holder. To view a copy of this licence, visit http://creativecommons.org/licenses/by/4.0/.

\section{References}

1. Emdin M, Vittorini S, Passino C, Clerico A (2009) Old and new biomarkers of heart failure. Eur J Heart Fail 11:331-335. https:// doi.org/10.1093/eurjhf/hfp035

2. Ponikowski P, Voors AA, Anker SD et al (2016) ESC Guidelines for the diagnosis and treatment of acute and chronic heart failure. Eur J Heart Fail 18:891-975. https://doi.org/10.1002/ejhf.592

3. Vasan RS (2006) Biomarkers of cardiovascular disease: molecular basis and practical considerations. Circulation 113:23352362. https://doi.org/10.1161/CIRCULATIONAHA.104.482570

4. Biomarkers Definitions Working Group (2001) Biomarkers and surrogate endpoints: preferred definitions and conceptual framework. Clin Pharmacol Ther 69:89-95. https://doi.org/10.1067/ mcp.2001.113989

5. International Programme on Chemical Safety (2001) Biomarkers in risk assessment: validity and validation. World Health Organization, Geneva

6. Morrow DA, de Lemos JA (2007) Benchmarks for the assessment of novel cardiovascular biomarkers. Circulation 115:949-952. https://doi.org/10.1161/CIRCULATIONAHA.106.683110

7. Ibrahim NE, Januzzi JL (2017) Beyond natriuretic peptides for diagnosis and management of heart failure. Clin Chem 63:211222. https://doi.org/10.1373/clinchem.2016.259564

8. Elster SK, Braunwald E, Wood HF (1956) A study of C-reactive protein in the serum of patients with congestive heart failure. Am Heart J 51:533-541. https://doi.org/10.1016/0002-8703(56) 90099-0

9. de Bold AJ, Borenstein HB, Veress AT, Sonnenberg H (1981) A rapid and potent natriuretic response to intravenous injection of atrial myocardial extract in rats. Life Sci 28:89-94. https://doi. org/10.1016/0024-3205(81)90370-2
10. Sudoh T, Kangawa K, Minamino N, Matsuo H (1988) A new natriuretic peptide in porcine brain. Nature 332:78-81. https:// doi.org/10.1038/332078a0

11. Goetze JP, Bruneau BG, Ramos HR et al (2020) Cardiac natriuretic peptides. Nat Rev Cardiol 17:698-717. https://doi.org/10. 1038/s41569-020-0381-0

12. Maisel AS, Krishnaswamy P, Nowak RM et al (2002) Rapid measurement of B-type natriuretic peptide in the emergency diagnosis of heart failure. N Engl J Med 347:161-167. https:// doi.org/10.1056/NEJMoa020233

13. Januzzi JL, Camargo CA, Anwaruddin S et al (2005) The $\mathrm{N}$-terminal Pro-BNP investigation of dyspnea in the emergency department (PRIDE) study. Am J Cardiol 95:948-954. https:// doi.org/10.1016/j.amjcard.2004.12.032

14. Januzzi JL, van Kimmenade R, Lainchbury J et al (2005) NTproBNP testing for diagnosis and short-term prognosis in acute destabilized heart failure: an international pooled analysis of 1256 patients: The International Collaborative of NT-proBNP Study. Eur Heart J 27:330-337. https://doi.org/10.1093/eurheartj/ ehi631

15. Zaphiriou A, Robb S, Murray-Thomas T et al (2005) The diagnostic accuracy of plasma BNP and NTproBNP in patients referred from primary care with suspected heart failure: Results of the UK natriuretic peptide study. Eur J Heart Fail 7:537-541. https://doi.org/10.1016/j.ejheart.2005.01.022

16. Hildebrandt P, Collinson P, Heart RD-E (2010) undefined Agedependent values of $\mathrm{N}$-terminal pro-B-type natriuretic peptide are superior to a single cut-point for ruling out suspected systolic dysfunction in primary care. academic.oup.com

17. Yancy CW, Jessup M, Bozkurt B et al (2017) 2017 ACC/AHA/ HFSA focused update of the 2013 ACCF/AHA guideline for the management of heart failure: a report of the American College of Cardiology/American Heart Association Task Force on Clinical Practice Guidelines and the Heart Failure Society of America. Circulation 136:e137-e161

18. Mueller C, McDonald K, de Boer RA et al (2019) Heart Failure Association of the European Society of Cardiology practical guidance on the use of natriuretic peptide concentrations. Eur J Heart Fail 21:715-731. https://doi.org/10.1002/ejhf.1494

19. Fonarow GC, Peacock WF, Phillips CO et al (2007) Admission B-type natriuretic peptide levels and in-hospital mortality in acute decompensated heart failure. J Am Coll Cardiol 49:19431950. https://doi.org/10.1016/j.jacc.2007.02.037

20. Januzzi JL, Sakhuja R, O'Donoghue M et al (2006) Utility of amino-terminal pro-brain natriuretic peptide testing for prediction of 1-year mortality in patients with dyspnea treated in the emergency department. Arch Intern Med 166:315-320. https:// doi.org/10.1001/archinte.166.3.315

21. Kociol RD, Horton JR, Fonarow GC et al (2011) Admission, discharge, or change in B-type natriuretic peptide and longterm outcomes: data from Organized Program to Initiate Lifesaving Treatment in Hospitalized Patients with Heart Failure (OPTIMIZE-HF) linked to Medicare claims. Circ Heart Fail 4:628-636. https://doi.org/10.1161/CIRCHEARTFAILURE. 111.962290

22. Michtalik HJ, Yeh H-C, Campbell CY et al (2011) Acute changes in $\mathrm{N}$-terminal pro-B-type natriuretic peptide during hospitalization and risk of readmission and mortality in patients with heart failure. Am J Cardiol 107:1191-1195. https://doi.org/10.1016/j. amjcard.2010.12.018

23. Cohen-Solal A, Logeart D, Huang B et al (2009) Lowered B-type natriuretic peptide in response to levosimendan or dobutamine treatment is associated with improved survival in patients with severe acutely decompensated heart failure. J Am Coll Cardiol 53:2343-2348. https://doi.org/10.1016/j.jacc.2009.02.058 
24. Masson S, Latini R, Anand IS et al (2006) Direct comparison of B-type natriuretic peptide (BNP) and amino-terminal proBNP in a large population of patients with chronic and symptomatic heart failure: the Valsartan Heart Failure (Val-HeFT) data. Clin Chem 52:1528-1538. https://doi.org/10.1373/clinchem.2006.069575

25. Vergaro G, Januzzi JL, Cohen Solal A et al (2018) NT-proBNP prognostic value is maintained in elderly and very elderly patients with chronic systolic heart failure. Int J Cardiol 271:324-330. https://doi.org/10.1016/j.ijcard.2018.04.006

26. Masson S, Latini R, Anand IS et al (2008) Prognostic value of changes in N-terminal pro-brain natriuretic peptide in Val-HeFT (Valsartan Heart Failure Trial). J Am Coll Cardiol 52:997-1003. https://doi.org/10.1016/j.jacc.2008.04.069

27. Aimo A, Gaggin HK, Barison A et al (2019) Imaging, biomarker, and clinical predictors of cardiac remodeling in heart failure with reduced ejection fraction. JACC Heart Fail 7:782-794. https:// doi.org/10.1016/j.jchf.2019.06.004

28. Daubert MA, Adams K, Yow E et al (2019) NT-proBNP goal achievement is associated with significant reverse remodeling and improved clinical outcomes in HFrEF. JACC Heart Fail 7:158-168. https://doi.org/10.1016/j.jchf.2018.10.014

29. Wang TJ, Larson MG, Levy D et al (2004) Plasma natriuretic peptide levels and the risk of cardiovascular events and death. N Engl J Med 350:655-663. https://doi.org/10.1056/NEJMoa031994

30. Omland T, Sabatine MS, Jablonski KA et al (2007) Prognostic value of B-type natriuretic peptides in patients with stable coronary artery disease: the PEACE Trial. J Am Coll Cardiol 50:205-214. https://doi.org/10.1016/j.jacc.2007.03.038

31. deFilippi CR, Christenson RH, Gottdiener JS et al (2010) Dynamic cardiovascular risk assessment in the elderly: the role of repeated amino terminal pro-B-type natriuretic peptide testing. J Am Coll Cardiol 55:441-450. https://doi.org/10.1016/j.jacc.2009.07.069

32. Ledwidge $M$, Gallagher J, Conlon C et al (2013) Natriuretic peptide-based screening and collaborative care for heart failure: the STOP-HF randomized trial. JAMA 310:66-74. https://doi. org/10.1001/jama.2013.7588

33. Huelsmann M, Neuhold S, Resl M et al (2013) PONTIAC (NTproBNP selected prevention of cardiac events in a population of diabetic patients without a history of cardiac disease): a prospective randomized controlled trial. J Am Coll Cardiol 62:13651372. https://doi.org/10.1016/j.jacc.2013.05.069

34. Ibrahim NE, Januzzi JL (2018) The Future of Biomarker-Guided Therapy for Heart Failure After the Guiding Evidence-Based Therapy Using Biomarker Intensified Treatment in Heart Failure (GUIDE-IT) Study. Curr Heart Fail Rep 15:37-43. https://doi. org/10.1007/s11897-018-0381-0

35. Murdoch DR, McDonagh TA, Byrne J et al (1999) Titration of vasodilator therapy in chronic heart failure according to plasma brain natriuretic peptide concentration: randomized comparison of the hemodynamic and neuroendocrine effects of tailored versus empirical therapy. Am Heart J 138:1126-1132. https://doi. org/10.1016/s0002-8703(99)70079-7

36. Troughton RW, Frampton CM, Brunner-La Rocca HP et al (2014) Effect of B-type natriuretic peptide-guided treatment of chronic heart failure on total mortality and hospitalization: an individual patient meta-analysis. Eur Heart J 35:1559-1567. https://doi.org/ 10.1093/eurheartj/ehu090

37. Felker GM, Hasselblad V, Hernandez AF, O'Connor CM (2009) Biomarker-guided therapy in chronic heart failure: a meta-analysis of randomized controlled trials. Am Heart J 158:422-430. https://doi.org/10.1016/j.ahj.2009.06.018

38. Savarese G, Trimarco B, Dellegrottaglie $S$ et al (2013) Natriuretic peptide-guided therapy in chronic heart failure: a meta-analysis of 2,686 patients in 12 randomized trials. PLoS ONE 8:e58287. https://doi.org/10.1371/journal.pone.0058287
39. Felker GM, Anstrom KJ, Adams KF et al (2017) Effect of natriuretic peptide-guided therapy on hospitalization or cardiovascular mortality in high-risk patients with heart failure and reduced ejection fraction: a randomized clinical trial. JAMA 318:713720. https://doi.org/10.1001/jama.2017.10565

40. Mark DB, Cowper PA, Anstrom KJ et al (2018) Economic and quality-of-life outcomes of natriuretic peptide-guided therapy for heart failure. J Am Coll Cardiol 72:2551-2562. https://doi.org/ 10.1016/j.jacc.2018.08.2184

41. Milton P (2003) Should B-type natriuretic peptide be measured routinely to guide the diagnosis and management of chronic heart failure? Circulation 108:2950-2953. https://doi.org/10.1161/01. CIR.0000109205.35813.8E

42. Maisel A, Mueller C, Nowak R et al (2010) Mid-region prohormone markers for diagnosis and prognosis in acute dyspnea. Results from the BACH (Biomarkers in Acute Heart Failure) Trial. J Am Coll Cardiol 55:2062-2076. https://doi.org/10. 1016/j.jacc.2010.02.025

43. Shah RV, Truong QA, Gaggin HK et al (2012) Mid-regional pro-atrial natriuretic peptide and pro-adrenomedullin testing for the diagnostic and prognostic evaluation of patients with acute dyspnoea. Eur Heart J 33:2197-2205. https://doi.org/10.1093/ eurheartj/ehs 136

44. von Haehling S, Jankowska EA, Morgenthaler NG et al (2007) Comparison of midregional pro-atrial natriuretic peptide with $\mathrm{N}$-terminal pro-B-type natriuretic peptide in predicting survival in patients with chronic heart failure. J Am Coll Cardiol 50:1973-1980. https://doi.org/10.1016/j.jacc.2007.08.012

45. Masson S, Latini R, Carbonieri E et al (2010) The predictive value of stable precursor fragments of vasoactive peptides in patients with chronic heart failure: data from the GISSI-heart failure (GISSI-HF) trial. Eur J Heart Fail 12:338-347. https://doi. org/10.1093/eurjhf/hfp206

46. Clerico A, Ry SD, Maffei S et al (2002) The circulating levels of cardiac natriuretic hormones in healthy adults: effects of age and sex 40:371-377. https://doi.org/10.1515/CCLM.2002.060

47. Maffei S, Del Ry S, Prontera C (1979) Clerico A (2001) Increase in circulating levels of cardiac natriuretic peptides after hormone replacement therapy in postmenopausal women. Clin Sci Lond Engl 101:447-453

48. Hsich EM, Grau-Sepulveda MV, Hernandez AF et al (2013) Relationship between sex, ejection fraction, and B-type natriuretic peptide levels in patients hospitalized with heart failure and associations with inhospital outcomes: findings from the Get With The Guideline-Heart Failure Registry. Am Heart J 166:1063-1071.e3. https://doi.org/10.1016/j.ahj.2013.08.029

49. Gupta DK, de Lemos JA, Ayers CR et al (2015) Racial Differences in Natriuretic Peptide Levels: The Dallas Heart Study. JACC Heart Fail 3:513-519. https://doi.org/10.1016/j.jchf.2015. 02.008

50. Krim SR, Vivo RP, Krim NR et al (2013) Racial/Ethnic differences in B-type natriuretic peptide levels and their association with care and outcomes among patients hospitalized with heart failure: findings from Get With The Guidelines-Heart Failure. JACC Heart Fail 1:345-352. https://doi.org/10.1016/j.jchf.2013. 04.008

51. Seidelmann SB, Vardeny O, Claggett B, et al (2017) An NPPB promoter polymorphism associated with elevated $\mathrm{N}$-terminal pro-B-type natriuretic peptide and lower blood pressure, hypertension, and mortality. J Am Heart Assoc 6. https://doi.org/10. 1161/JAHA.116.005257

52. Newton-Cheh C, Larson MG, Vasan RS et al (2009) Association of common variants in NPPA and NPPB with circulating natriuretic peptides and blood pressure. Nat Genet 41:348-353. https://doi.org/10.1038/ng.328 
53. McCullough PA, Duc P, Omland T et al (2003) B-type natriuretic peptide and renal function in the diagnosis of heart failure: An analysis from the breathing not properly multinational study. Am J Kidney Dis 41:571-579. https://doi.org/10.1053/ajkd. 2003.50118

54. Ibrahim NE, McCarthy CP, Shrestha S et al (2019) Effect of Neprilysin Inhibition on Various Natriuretic Peptide Assays. J Am Coll Cardiol 73:1273-1284. https://doi.org/10.1016/j.jacc. 2018.12.063

55. Aimo A, Januzzi JL, Vergaro G et al (2019) Revisiting the obesity paradox in heart failure: Per cent body fat as predictor of biomarkers and outcome. Eur J Prev Cardiol 26:1751-1759. https://doi. org/10.1177/2047487319852809

56. Braunwald E (2008) Biomarkers in heart failure. N Engl J Med 358:2148-2159. https://doi.org/10.1056/NEJMra0800239

57. Cohn JN, Levine TB, Olivari MT et al (1984) Plasma norepinephrine as a guide to prognosis in patients with chronic congestive heart failure. N Engl J Med 311:819-823. https://doi.org/10. 1056/NEJM198409273111303

58. Francis GS, Cohn JN, Johnson G, et al (1993) Plasma norepinephrine, plasma renin activity, and congestive heart failure. Relations to survival and the effects of therapy in V-HeFT II. The V-HeFT VA Cooperative Studies Group. Circulation 87:VI40-8

59. Cabassi A, De CJ, Maggiore U et al (2013) Prealbumin improves death risk prediction of BNP-added Seattle Heart Failure Model: results from a pilot study in elderly chronic heart failure patients. Int J Cardiol 168:3334-3339. https://doi.org/10.1016/j.jjcard.2013.04.039

60. Ceconi C, Ferrari R, Bachetti T et al (2002) Chromogranin A in heart failure; a novel neurohumoral factor and a predictor for mortality. Eur Heart J 23:967-974. https://doi.org/10.1053/euhj.2001.2977

61. Røsjø H, Husberg C, Dahl MB et al (2010) Chromogranin B in heart failure: a putative cardiac biomarker expressed in the failing myocardium. Circ Heart Fail 3:503-511. https://doi.org/10.1161/ CIRCHEARTFAILURE.109.867747

62. Vergaro G, Emdin M, Iervasi A et al (2011) Prognostic value of plasma renin activity in heart failure. Am J Cardiol 108:246-251. https://doi.org/10.1016/j.amjcard.2011.03.034

63. Vaduganathan M, Cheema B, Cleveland E et al (2018) Plasma renin activity, response to aliskiren, and clinical outcomes in patients hospitalized for heart failure: the ASTRONAUT trial. Eur J Heart Fail 20:677-686. https://doi.org/10.1002/ejhf.973

64. Voors AA, Kremer D, Geven C et al (2019) Adrenomedullin in heart failure: pathophysiology and therapeutic application. Eur J Heart Fail 21:163-171. https://doi.org/10.1002/ejhf.1366

65. Richards AM, Doughty R, Nicholls MG et al (2001) Plasma $\mathrm{N}$-terminal pro-brain natriuretic peptide and adrenomedullin: Prognostic utility and prediction of benefit from carvedilol in chronic ischemic left ventricular dysfunction. J Am Coll Cardiol 37:1781-1787. https://doi.org/10.1016/S0735-1097(01)01269-4

66. von Haehling S, Filippatos GS, Papassotiriou J et al (2010) Midregional pro-adrenomedullin as a novel predictor of mortality in patients with chronic heart failure. Eur J Heart Fail 12:484-491. https://doi.org/10.1093/eurjhf/hfq031

67. Chatterjee K (2005) Neurohormonal activation in congestive heart failure and the role of vasopressin. Am J Cardiol 95:8-13. https://doi.org/10.1016/j.amjcard.2005.03.003

68. Maisel A, Xue Y, Shah K et al (2011) Increased 90-day mortality in patients with acute heart failure with elevated copeptin: secondary results from the Biomarkers in Acute Heart Failure (BACH) study. Circ Heart Fail 4:613-620. https://doi.org/10. 1161/CIRCHEARTFAILURE.110.960096

69. Zhong Y, Wang R, Yan L et al (2017) Copeptin in heart failure: review and meta-analysis. Clin Chim Acta 475:36-43

70. Zhang CL, Xie S, Qiao X, et al (2017) Plasma endothelin-1related peptides as the prognostic biomarkers for heart failure: a
PRISMA-compliant meta-analysis. Med U S 96. https://doi.org/ 10.1097/MD.0000000000009342

71. Perez AL, Grodin JL, Wu Y et al (2016) Increased mortality with elevated plasma endothelin-1 in acute heart failure: an ASCENDHF biomarker substudy. Eur J Heart Fail 18:290-297. https://doi. org/10.1002/ejhf.456

72. Gaggin HK, Truong QA, Gandhi PU et al (2017) Systematic evaluation of endothelin 1 measurement relative to traditional and modern biomarkers for clinical assessment and prognosis in patients with chronic systolic heart failure: serial measurement and multimarker testing. Am J Clin Pathol 147:461-472. https:// doi.org/10.1093/AJCP/AQX014

73. Rademaker MT, Richards AM (2017) Urocortins: actions in health and heart failure. Clin Chim Acta 474:76-87

74. Chow SL, Maisel AS, Anand I et al (2017) Role of biomarkers for the prevention, assessment, and management of heart failure: A scientific statement from the American Heart Association. Circulation 135:e1054-e1091. https://doi.org/10.1161/CIR. 0000000000000490

75. Xue Y, Clopton P, Peacock WF, Maisel AS (2011) Serial changes in high-sensitive troponin I predict outcome in patients with decompensated heart failure. Eur J Heart Fail 13:37-42. https:// doi.org/10.1093/eurjhf/hfq210

76. Pascual-Figal DA, Casas T, Ordonez-Llanos J et al (2012) Highly sensitive troponin $\mathrm{T}$ for risk stratification of acutely destabilized heart failure. Am Heart J 163:1002-1010. https://doi.org/10. 1016/j.ahj.2012.03.015

77. Aimo A, Januzzi JL, Mueller C et al (2019) Admission highsensitivity troponin T and NT-proBNP for outcome prediction in acute heart failure. Int J Cardiol 293:137-142. https://doi.org/ 10.1016/j.ijcard.2019.06.005

78. Latini R, Masson S, Anand IS et al (2007) Prognostic value of very low plasma concentrations of troponin $\mathrm{T}$ in patients with stable chronic heart failure. Circulation 116:1242-1249. https:// doi.org/10.1161/CIRCULATIONAHA.106.655076

79. Aimo A, Januzzi JL, Vergaro G et al (2018) Prognostic value of high-sensitivity troponin $\mathrm{T}$ in chronic heart failure: an individual patient data meta-analysis. Circulation 137:286-297. https://doi. org/10.1161/CIRCULATIONAHA.117.031560

80. Evans JDW, Dobbin SJH, Pettit SJ et al (2018) High-sensitivity cardiac troponin and new-onset heart failure: a systematic review and meta-analysis of 67,063 patients with 4,165 incident heart failure events. JACC Heart Fail 6:187-197. https://doi.org/10. 1016/j.jchf.2017.11.003

81. Aimo A, Januzzi JL, Bayes-Genis A et al (2019) Clinical and prognostic significance of sST2 in heart failure: JACC review topic of the week. J Am Coll Cardiol 74:2193-2203

82. Aimo A, Vergaro G, Ripoli A et al (2017) Meta-analysis of soluble suppression of tumorigenicity-2 and prognosis in acute heart failure. JACC Heart Fail 5:287-296. https://doi.org/10.1016/j. jchf.2016.12.016

83. Boisot S, Beede J, Isakson S et al (2008) Serial sampling of ST2 predicts 90-day mortality following destabilized heart failure. J Card Fail 14:732-738. https://doi.org/10.1016/j.cardfail.2008.06.415

84. van Vark LC, Lesman-Leegte I, Baart SJ et al (2017) Prognostic value of serial ST2 measurements in patients with acute heart failure. J Am Coll Cardiol 70:2378-2388. https://doi.org/10. 1016/j.jacc.2017.09.026

85. Emdin M, Aimo A, Vergaro G et al (2018) sST2 predicts outcome in chronic heart failure beyond NT-proBNP and highsensitivity troponin T. J Am Coll Cardiol 72:2309-2320. https:// doi.org/10.1016/j.jacc.2018.08.2165

86. Aimo A, Januzzi JL, Vergaro G, et al (2020) Circulating levels and prognostic value of soluble ST2 in heart failure are less influenced by age than $\mathrm{N}$-terminal pro-B-type natriuretic peptide and 
high-sensitivity troponin T. Eur J Heart Fail ejhf.1701. https:// doi.org/10.1002/ejhf.1701

87. Aimo A, Maisel AS, Castiglione V, Emdin M (2019) sST2 for outcome prediction in acute heart failure: which is the best cutoff? J Am Coll Cardiol 74:478-479

88. Vergaro G, Prud'Homme M, Fazal L et al (2016) Inhibition of galectin-3 pathway prevents isoproterenol-induced left ventricular dysfunction and fibrosis in mice. Hypertension 67:606-612. https://doi.org/10.1161/HYPERTENSIONAHA.115.06161

89. Meijers WC, Januzzi JL, Defilippi C et al (2014) Elevated plasma galectin-3 is associated with near-term rehospitalization in heart failure: a pooled analysis of 3 clinical trials. Am Heart J 167:853860.e4. https://doi.org/10.1016/j.ahj.2014.02.011

90. Miró Ò, González de la Presa B, Herrero-Puente P et al (2017) The GALA study: relationship between galectin-3 serum levels and short- and long-term outcomes of patients with acute heart failure. Biomarkers 22:731-739. https://doi.org/10.1080/ 1354750X.2017.1319421

91. Gehlken C, Suthahar N, Meijers WC, de Boer RA (2018) Galectin3 in heart failure: an update of the last 3 years. Heart Fail Clin 14:75-92

92. Cotter G, Voors AA, Prescott MF et al (2015) Growth differentiation factor 15 (GDF-15) in patients admitted for acute heart failure: results from the RELAX-AHF study. Eur J Heart Fail 17:1133-1143. https://doi.org/10.1002/ejhf.331

93. Kempf T, von Haehling S, Peter T et al (2007) Prognostic utility of growth differentiation factor- 15 in patients with chronic heart failure. J Am Coll Cardiol 50:1054-1060. https://doi.org/ 10.1016/j.jacc.2007.04.091

94. Anand IS, Kempf T, Rector TS et al (2010) Serial measurement of growth-differentiation factor-15 in heart failure: relation to disease severity and prognosis in the Valsartan Heart Failure Trial. Circulation 122:1387-1395. https://doi.org/10.1161/ CIRCULATIONAHA.109.928846

95. Santema BT, Chan MMY, Tromp J et al (2020) The influence of atrial fibrillation on the levels of NT-proBNP versus GDF-15 in patients with heart failure. Clin Res Cardiol 109:331-338. https://doi.org/10.1007/s00392-019-01513-y

96. Zile MR, DeSantis SM, Baicu CF et al (2011) Plasma biomarkers that reflect determinants of matrix composition identify the presence of left ventricular hypertrophy and diastolic heart failure. Circ Heart Fail 4:246-256. https://doi.org/10.1161/ CIRCHEARTFAILURE.110.958199

97. Zannad F, Alla F, Dousset B et al (2000) Limitation of excessive extracellular matrix turnover may contribute to survival benefit of spironolactone therapy in patients with congestive heart failure. Circulation 102:2700-2706. https://doi.org/10.1161/01.CIR. 102.22.2700

98. Cunningham JW, Claggett BL, O'Meara E et al (2020) Effect of sacubitril/valsartan on biomarkers of extracellular matrix regulation in patients with HFpEF. J Am Coll Cardiol 76:503-514. https://doi.org/10.1016/j.jacc.2020.05.072

99. Aimo A, Castiglione V, Borrelli C et al (2020) Oxidative stress and inflammation in the evolution of heart failure: From pathophysiology to therapeutic strategies. Eur J Prev Cardiol 27:494510. https://doi.org/10.1177/2047487319870344

100. Vasan RS, Sullivan LM, Roubenoff R et al (2003) Inflammatory markers and risk of heart failure in elderly subjects without prior myocardial infarction: The Framingham Heart Study. Circulation 107:1486-1491. https://doi.org/10.1161/01.CIR.0000057810. 48709.F6

101. Cesari M, Penninx BWJH, Newman AB et al (2003) Inflammatory markers and onset of cardiovascular events: results from the Health ABC Study. Circulation 108:2317-2322. https://doi.org/ 10.1161/01.CIR.0000097109.90783.FC
102. Núñez J, Bayés-Genís A, Revuelta-López E et al (2020) Clinical role of CA125 in worsening heart failure: a BIOSTAT-CHF study subanalysis. JACC Heart Fail 8:386-397. https://doi.org/ 10.1016/j.jchf.2019.12.005

103. Tang WHW, Brennan ML, Philip K et al (2006) Plasma myeloperoxidase levels in patients with chronic heart failure. Am J Cardiol 98:796-799. https://doi.org/10.1016/j.amjcard.2006.04.018

104. Reichlin T, Socrates T, Egli P et al (2010) Use of myeloperoxidase for risk stratification in acute heart failure. Clin Chem 56:944-951. https://doi.org/10.1373/clinchem.2009.142257

105. Aimo A, Januzzi JL, Vergaro G et al (2019) High-sensitivity troponin T, NT-proBNP and glomerular filtration rate: A multimarker strategy for risk stratification in chronic heart failure. Int J Cardiol 277:166-172. https://doi.org/10.1016/j.ijcard. 2018.10.079

106. Kim TH, Kim H, Kim IC (2015) The potential of cystatin-C to evaluate the prognosis of acute heart failure: A comparative study. Acute Card Care 17:72-76. https://doi.org/10.1080/17482 941.2016.1203440

107. Dupont M, Wu Y, Hazen SL, Wilson Tang WH (2012) Cystatin $\mathrm{C}$ identifies patients with stable chronic heart failure at increased risk for adverse cardiovascular events. Circ Heart Fail 5:602-609. https://doi.org/10.1161/CIRCHEARTFAILURE. 112.966960

108. Alvelos M, Lourenço P, Dias C et al (2013) Prognostic value of neutrophil gelatinase-associated lipocalin in acute heart failure. Int J Cardiol 165:51-55. https://doi.org/10.1016/j.ijcard.2011. 07.080

109. Jungbauer CG, Birner C, Jung B et al (2011) Kidney injury molecule- 1 and $\mathrm{N}$-acetyl- $\beta$-D-glucosaminidase in chronic heart failure: possible biomarkers of cardiorenal syndrome. Eur J Heart Fail 13:1104-1110. https://doi.org/10.1093/eurjhf/hfr102

110. Damman K, Masson S, Hillege HL et al (2011) Clinical outcome of renal tubular damage in chronic heart failure $\dagger$. Eur Heart J 32:2705-2712. https://doi.org/10.1093/eurheartj/ehr190

111. Vergaro G, Aimo A, Passino C, Emdin M (2018) Heart, kidney and FGF23: Les liaisons dangereuses. Int J Cardiol 253:120-121

112. Fauconnier C, Roy T, Gillerot G et al (2019) FGF23: Clinical usefulness and analytical evolution. Clin Biochem 66:1-12

113. Uthamalingam S, Kandala J, Daley M et al (2010) Serum albumin and mortality in acutely decompensated heart failure. Am Heart J 160:1149-1155. https://doi.org/10.1016/j. ahj.2010.09.004

114. Allen LA, Felker GM, Pocock S et al (2009) Liver function abnormalities and outcome in patients with chronic heart failure: data from the Candesartan in Heart Failure: Assessment of Reduction in Mortality and Morbidity (CHARM) program. Eur J Heart Fail 11:170-177. https://doi.org/10.1093/eurjhf/hfn031

115. Baggish AL, van Kimmenade R, Bayes-Genis A et al (2007) Hemoglobin and N-terminal pro-brain natriuretic peptide: Independent and synergistic predictors of mortality in patients with acute heart failure. Results from the International Collaborative of NT-proBNP (ICON) Study. Clin Chim Acta 381:145-150. https://doi.org/10.1016/j.cca.2007.03.010

116. Anand I, McMurray JJV, Whitmore J et al (2004) Anemia and its relationship to clinical outcome in heart failure. Circulation 110:149154. https://doi.org/10.1161/01.CIR.0000134279.79571.73

117. Klip IT, Comin-Colet J, Voors AA et al (2013) Iron deficiency in chronic heart failure: An international pooled analysis. Am Heart J 165:575-582.e3. https://doi.org/10.1016/j.ahj.2013.01.017

118. McDonagh T, Damy T, Doehner W et al (2018) Screening, diagnosis and treatment of iron deficiency in chronic heart failure: putting the 2016 European Society of Cardiology heart failure guidelines into clinical practice. Eur J Heart Fail 20:1664-1672. https://doi.org/10.1002/ejhf.1305 
119. Kannan L, Shaw PA, Morley MP et al (2018) Thyroid dysfunction in heart failure and cardiovascular outcomes. Circ Heart Fail 11:e005266. https://doi.org/10.1161/CIRCHEARTFAILURE. 118.005266

120. Emdin M, Barison A, Aimo A (2020) Thyroid, heart failure, and neuroendocrine activation. In: Thyroid and heart. Springer International Publishing, pp 301-309

121. Güder G, Bauersachs J, Frantz S et al (2007) Complementary and incremental mortality risk prediction by cortisol and aldosterone in chronic heart failure. Circulation 115:1754-1761. https://doi. org/10.1161/CIRCULATIONAHA.106.653964

122. Hammer F, Deutschbein T, Marx A et al (2016) High evening salivary cortisol is an independent predictor of increased mortality risk in patients with systolic heart failure. Int J Cardiol 203:69-73. https://doi.org/10.1016/j.ijcard.2015.10.084

123. Tsutamoto T, Tanaka T, Sakai H et al (2007) Total and high molecular weight adiponectin, haemodynamics, and mortality in patients with chronic heart failure. Eur Heart J 28:1723-1730. https://doi.org/10.1093/eurheartj/ehm154

124. Kistorp C, Faber J, Galatius S, et al (2005) Plasma adiponectin, body mass index, and mortality in patients with chronic heart failure. https://doi.org/10.1161/CIRCULATIONAHA.104. 530972

125. Demissei BG, Cotter G, Prescott MF et al (2017) A multimarker multi-time point-based risk stratification strategy in acute heart failure: results from the RELAX-AHF trial. Eur J Heart Fail 19:1001-1010. https://doi.org/10.1002/ejhf.749

126. Brouwers FP, Van Gilst WH, Damman K et al (2014) Clinical risk stratification optimizes value of biomarkers to predict newonset heart failure in a community-based cohort. Circ Heart Fail 7:723-731. https://doi.org/10.1161/CIRCHEARTFAILURE.114. 001185

127. Velagaleti RS, Gona P, Larson MG et al (2010) Multimarker approach for the prediction of heart failure incidence in the community. Circulation 122:1700-1706. https://doi.org/10.1161/ CIRCULATIONAHA.109.929661

128. Ibrahim NE, Januzzi JL (2018) Established and emerging roles of biomarkers in heart failure. Circ Res 123:614-629. https://doi. org/10.1161/CIRCRESAHA.118.312706

129. Sarhene M, Wang Y, Wei J et al (2019) Biomarkers in heart failure: the past, current and future. Heart Fail Rev 24:867-903. https://doi.org/10.1007/s10741-019-09807-z

130. Chirinos JA, Orlenko A, Zhao L et al (2020) Multiple plasma biomarkers for risk stratification in patients with heart failure and preserved ejection fraction. J Am Coll Cardiol 75:1281-1295. https://doi.org/10.1016/j.jacc.2019.12.069

131. Bayes-Genis A, Liu PP, Lanfear DE et al (2020) Omics phenotyping in heart failure: the next frontier. Eur Heart J 41:3477-3484. https://doi.org/10.1093/eurheartj/ehaa270
132. van der Ende MY, Said MA, van Veldhuisen DJ et al (2018) Genome-wide studies of heart failure and endophenotypes: lessons learned and future directions. Cardiovasc Res 114:12091225. https://doi.org/10.1093/cvr/cvy083

133. Meder B, Haas J, Sedaghat-Hamedani F et al (2017) Epigenomewide association study identifies cardiac gene patterning and a novel class of biomarkers for heart failure. Circulation 136:1528 1544. https://doi.org/10.1161/CIRCULATIONAHA.117.027355

134. Toma M, Mak GJ, Chen V et al (2017) Differentiating heart failure phenotypes using sex-specific transcriptomic and proteomic biomarker panels. ESC Heart Fail 4:301-311. https://doi.org/10. 1002/ehf2.12136

135. Zhou SS, Jin JP, Wang JQ et al (2018) miRNAS in cardiovascular diseases: potential biomarkers, therapeutic targets and challenges. Acta Pharmacol Sin 39:1073-1084. https://doi.org/10. 1038/aps.2018.30

136. Mebazaa A, Vanpoucke G, Thomas G et al (2012) Unbiased plasma proteomics for novel diagnostic biomarkers in cardiovascular disease: identification of quiescin Q6 as a candidate biomarker of acutely decompensated heart failure. Eur Heart J 33:2317-2324. https://doi.org/10.1093/eurheartj/ehs162

137. Stenemo M, Nowak C, Byberg L et al (2018) Circulating proteins as predictors of incident heart failure in the elderly. Eur J Heart Fail 20:55-62. https://doi.org/10.1002/ejhf.980

138. Adamo L, Yu J, Rocha-Resende C et al (2020) Proteomic Signatures of Heart Failure in Relation to Left Ventricular Ejection Fraction. J Am Coll Cardiol 76:1982-1994. https://doi.org/10. 1016/j.jacc.2020.08.061

139. Hunter WG, Kelly JP, McGarrah RW, et al (2016) Metabolomic Profiling Identifies Novel Circulating Biomarkers of Mitochondrial Dysfunction Differentially Elevated in Heart Failure With Preserved Versus Reduced Ejection Fraction: Evidence for Shared Metabolic Impairments in Clinical Heart Failure. J Am Heart Assoc 5. https://doi.org/10.1161/JAHA.115.003190

140. Ahmad T, Kelly JP, McGarrah RW et al (2016) Prognostic Implications of Long-Chain Acylcarnitines in Heart Failure and Reversibility With Mechanical Circulatory Support. J Am Coll Cardiol 67:291-299. https://doi.org/10.1016/j.jacc.2015.10.079

141. Lanfear DE, Gibbs JJ, Li J et al (2017) Targeted metabolomic profiling of plasma and survival in heart failure patients. JACC Heart Fail 5:823-832. https://doi.org/10.1016/j.jchf.2017.07.009

Publisher's Note Springer Nature remains neutral with regard to jurisdictional claims in published maps and institutional affiliations. 